\title{
The Language and Literacy Development of Young Dual Language Learners: A Critical Review
}

\author{
Carol Scheffner Hammer, \\ Temple University, Davis \\ Erika Hoff, \\ Florida Atlantic University, Davis \\ Yuuko Uchikoshi, \\ University of California, Davis \\ Cristina Gillanders, \\ University of North Carolina, Chapel Hill \\ Dina Castro, and \\ Arizona State University

\section{Lia E. Sandilos} \\ Temple University
}

\section{Abstract}

The number of children living in the United States who are learning two languages is increasing greatly. However, relatively little research has been conducted on the language and literacy development of dual language learners (DLLs), particularly during the early childhood years. To summarize the extant literature and guide future research, a critical analysis of the literature was conducted. A search of major databases for studies on young typically developing DLLs between 2000-2011 yielded 182 peer-reviewed articles. Findings about DLL children's developmental trajectories in the various areas of language and literacy are presented. Much of these findings should be considered preliminary, because there were few areas where multiple studies were conducted. Conclusions were reached when sufficient evidence existed in a particular area. First, the research shows that DLLs have two separate language systems early in life. Second, differences in some areas of language development, such as vocabulary, appear to exist among DLLs depending on when they were first exposed to their second language. Third, DLLs' language and literacy development may differ from that of monolinguals, although DLLs appear to catch up over time. Fourth, little is known about factors that influence DLLs' development, although the amount of language exposure to and usage of DLLs' two languages appears to play key roles. Methodological issues are addressed, and directions for future research are discussed.

(C) 2014 Elsevier Inc. All rights reserved.

Publisher's Disclaimer: This is a PDF file of an unedited manuscript that has been accepted for publication. As a service to our customers we are providing this early version of the manuscript. The manuscript will undergo copyediting, typesetting, and review of the resulting proof before it is published in its final citable form. Please note that during the production process errors may be discovered which could affect the content, and all legal disclaimers that apply to the journal pertain. 


\section{Keywords}

bilingual; Dual Language Learners; language development; literacy

Children's oral language and early literacy development serve as the foundation for later reading abilities and overall academic success. It is well documented that children with low oral language abilities are at risk for poor outcomes as they progress through school (Snow, Burns, \& Griffin, 1998). Much research has examined the language and literacy development of children learning one language. Unfortunately, insufficient attention has been paid to the language and literacy development of children learning two languages or dual language learners (DLLs), particularly during the early childhood years. This is a crucial issue, because children who are DLLs represent one of the fastest growing populations in the United States (Basterra, Trumbull, \& Solano-Flores, 2010). Nearly 30\% of children in Head Start are DLLs, with $85 \%$ being speakers of Spanish (Mathematica Policy Research, 2010). This percentage is expected to increase over the next several decades.

Children learning two languages vary widely in their early experiences with their two languages. As a result, they are extremely heterogeneous in the language and early literacy abilities they possess when they enter kindergarten. Given that children's academic success is dependent on children's early language and literacy abilities, understanding the abilities of this substantial segment of the population is essential. There is particular reason to be concerned about DLLs in this regard. On average, children in the U.S. who speak English and also are exposed another language at home show lower levels of academic achievement throughout school and graduate high school at lower rates than monolingual Englishspeaking children (National Center for Education Statistics, 2013; Oller \& Eilers, 2002). Additionally, research has shown that DLLs' English language abilities in kindergarten predict their academic achievement trajectories through eighth grade (Halle, Hair, Wandener, McNamara, \& Chien, 2012; Han, 2012).

Home language and literacy skills are also relevant to DLLs' long-term outcomes. In immigrant families, children's abilities to speak their families' home languages are related to the quality of relationships within the family and to measures of psychosocial adjustment (Tseng \& Fuligni, 2000). Additionally, some literacy-related skills transfer across languages making strong home language skills of use in acquiring English literacy (Bialystok \& Herman, 1999; Hammer, Davison, Lawrence, \& Miccio, 2009; Riches \& Genesee, 2006). Furthermore, DLLs have a unique opportunity to become proficient bilinguals as adults and enjoy the attendant cognitive, social, and economic benefits (Bialystok, 2009).

Improving the field's understanding of the language and literacy development of young DLLs' language and literacy skills is critical, given the importance of these areas to later academic success (Scarborough, 2001; Snow et al., 1998). Such information will assist educators, researchers, and policy makers in understanding the developmental trajectories of DLLs and can be used to help understand when DLLs have learning concerns. Therefore, this manuscript presents the results of a critical review of the research literature from 20002011 on the early language and literacy development of DLLs. 
Critical reviews of DLLs' development have been done previously; however, none have focused on the language and literacy development of children from birth through age five. August and Shanahan's (2006) Report of the National Literacy Panel on Language-Minority Children and Youth reviewed research articles published between 1980 and 2002 that targeted elementary school children, with some studies of preschoolers being included. More recently, Dixon and colleagues (2012) synthesized information from four bodies of work: foreign language education, child language research, sociocultural studies, and psycholinguistics to highlight an integrated understanding across typically isolated perspectives on the optimal conditions for second language acquisition. Studies included in the review targeted children of various ages from preschool through twelfth grade.

Therefore, this critical review fills an important need by analyzing the recent research literature on the language and literacy development of DLLs from birth through age five. Specifically, the purpose was to: (a) synthesize the research findings on the trajectories of DLLs' language and literacy development and factors that influence these areas of development, (b) identify methodological concerns, and (c) identify gaps in the research base and determine future research needs.

\section{Method}

For the purposes of the critical literature review on language and literacy development, dual language learners were broadly defined as children who were exposed to two languages during early childhood (Bialystok, 2001). This includes children who were exposed to two languages from birth as well as children who were exposed to their second language sometime during the preschool years. There are two primary reasons for this inclusive definition. First, the research community has not developed an agreed upon definition of who is a dual language learner. A researcher's theoretical perspective and associated research question(s) often dictate the definition of DLLs used in an investigation. Second, in much of the research on DLLs' language and literacy development, descriptions of existing research samples often do not include inclusion/exclusion criteria. Therefore, many valuable studies would have been excluded from the review if a strict definition of DLL were applied.

The criteria used to identify articles included in this review were based on those defined by the Center for Early Care and Education Research-DLL. These included the following: published peer-reviewed journal articles from 2000-2011; a focus on typically-developing DLLs from birth through five years of age (with studies focusing only on kindergarteners excluded); a measurement plan that included at least one assessment point during this age span; analyses that focused on DLLs either exclusively or as a subgroup; and research designs that included case study, descriptive, cross-sectional, longitudinal, and qualitative methods. (Note that on a few occasions, findings on older children are reported when a study compared data on preschoolers as well as on older children. In these instances, the findings on preschoolers would be meaningless without a discussion of the findings on children of older ages.)

Prior to searching the literature, a list of key search terms was developed by the team, which consisted of the four authors of this paper. The terms were divided into 40 superordinate 
terms or primary search terms and 143 subordinate or secondary terms. The superordinate terms consisted of terms that focused on the targeted population (e.g., dual language learn*, bilingual, English language learn*, English language learn*, limited English proficiency), age groups (infant*, toddler*, preschool*, early childhood, early development, Head Start), and languages and cultures (e.g., Spanish-speaking, Latino, Chinese-speaking, Mandarin, language minorit*). The subordinate terms consisted of terms specific to contemporary academic vocabulary in the fields of language and literacy development, as well as terms that captured the influence of home and family on these areas of development. There were 78 language terms (e.g., phonetic*, phonology, prosody, vocabulary, auditory process*), 20 literacy terms (e.g., alphabetic principle, book reading, concepts of print, early reading, letter knowledge, reading), and 35 home and family terms (e.g., caregiver interaction, home literacy environment, middle-SES, famil*, parent*).

Next, a systematic search protocol was followed using both superordinate and subordinate search terms. Multiple searches were run across the major academic databases to identify all possible national and international articles that were available through search engines commonly used in the United States. The following databases were used to conduct the search: CINAHL, Elsevier, ERIC, Google Scholar, Linguistics and Language Behavior Abstracts, Medline, PsychInfo and PubMed. The search was limited to journals published in English that were available through these search engines.

The searches returned 3,543 unique citations published in English-language journals. Each citation was passed through multiple levels of review. An abstract was printed for every citation returned in the database search. These abstracts were then read by the first author and marked for inclusion or exclusion using the team's criteria. Articles that clearly did not meet the criteria were excluded by the first author $(N=3,082$; e.g., intervention studies, studies focusing on kindergarteners or older children, etc.). Following this, 461 full articles were obtained and sent to members of the research team. Team members then read the articles in their assigned areas (e.g., language articles on birth to three populations, language articles on three- to five-year olds, studies targeting Asian languages, and literacy) and made further exclusions using the review criteria as necessary. During this step of the process, articles that clearly did not meet the inclusion/exclusion criteria were discussed by the team as a whole. A decision was made by consensus about whether or not the article should be included. Through this process, 92 articles that focused on DLL populations in the United States and 90 articles on international DLL populations were chosen.

To assist with the critical review, information from each article was coded and entered into a table. Information extracted from the articles included: the purpose and design of the study; the languages studied; the sample including sample size, ages studied, and characteristics of the sample; definition of DLLs used; constructs and outcome measures; results; limitations; and implications/conclusions.

Three graduate students in Communication Sciences and Disorders were trained on the coding procedures and were closely supervised by the first author, who met with the students on a weekly basis. The graduate students entered the information about each article into the table with the exception of coding the results, limitations, and implications/ 
conclusions. Once the students completed the initial portion of the table, the table was shared with the members of the research team. Each team member assumed responsibility for articles within her area of expertise. The team members reviewed the graduate students' coding of their assigned articles, revised the entries as needed, and then completed the results, limitations, and implications/conclusions sections. The table is provided in the online supplemental material to this manuscript.

\section{Results}

Before summarizing the findings, a brief discussion about terminology is needed. First, it should be pointed out that a number of terms were used to refer to children who were learning two languages in the studies included in this review, such as DLLs, bilinguals, English language learners, and second language learners. For consistency, we decided to use DLL when summarizing the specific findings of the studies. Second, the term infant/toddler is used to refer to findings on children from birth through two years and eleven months of age. Preschooler refers to children from three through five years of age.

\section{Description of the Samples in the Articles Reviewed}

The samples found in the articles varied in terms of the languages spoken, DLL status and socio-demographic characteristics. The vast majority of the articles focused on DLLs who were learning English as a second language $(N=152,84 \%)$. The most commonly studied non-English language was Spanish $(N=81,45 \%)$, with 63 studies being conducted in the United States and of those, two involved children living in Puerto Rico. The dialect of Spanish varied among studies, although a large number of studies did not identify the dialect spoken by the children. Fifty-three (29\%) of the articles included DLL children learning to speak an Asian language: Chinese $(N=23 ; 10$ Mandarin, 6 Cantonese, 7 no dialect specified), Korean $(N=6)$, Persian/Farsi $(N=4)$, Turkish $(N=9)$, Japanese, $(N=3)$, Hmong $(N=3)$, Arabic $(N=2)$, Hebrew $(N=1)$, Gujarati $(N=1)$, Urdu $(N=1)$, Moroccan Arabic $(N=1)$ Tongan $(N=1)$, Samoan $(N=2)$, Marathi $(N=1)$, and East Indian language not specified $(N=1)$. Sixty-nine (38\%) of the studies focused on DLL children learning European languages: French $(N=27)$, German $(N=12)$, Catalan $(N=8)$, Italian $(N=7)$, Dutch $(N=6)$, Russian $(N=4)$, Swedish $(N=1)$, Greek $(N=1)$, Welsh $(N=1)$, Finnish $(N$ $=1)$, and Norwegian $(N=1)$. Two studies focused on indigenous languages, with one focusing on children learning Inuktitut, and another study focusing on Lajamanu Warlpiri and Light Warlpiri. Thirteen (7\%) of the articles combined DLL children who spoke a variety of languages into one group. These articles focused on children's development of English. (Note that an article could include two to three groups of DLLs who spoke different languages. Thus the percentages reported above total more than 100\%).

As alluded to earlier, the studies reviewed focused on children who were labeled using a variety of terms, including, but not limited to dual language learners, English language learners, bilingual children, Spanish-speaking children, etc. Consistent definitions of the various terms were not used, and in some cases, specific criteria were not established when labeling children. Children were simply labeled with the term chosen by the authors without further definition. In addition, the amount of information provided about the children's dual 
language exposure and usage varied. Ninety-three (51\%) of the studies specified whether children were simultaneous learners (i.e., children who learn two languages from birth) or sequential language learners (i.e., children who learn their home language from birth and their second language at age three or later). Fifty-two (29\%) of the articles provided information about the amount of exposure children had to their two languages, with more recent articles being more likely to include this information.

The samples also varied with regard to their socio-economic status (SES), although the SES of the children was not always specified. Only 60 (32\%) of the studies provided information about maternal education; 84 (46\%) included information about SES (as indicated by maternal education level and/or income). In general, the majority of studies conducted in the US that specified the sample's SES involved children of low-SES. The exceptions to this were case studies, which typically focused on children of high SES, often the authors' own children. With regard to articles on samples from outside the U.S., many of the studies included children from middle-SES backgrounds and/or who spoke the dominant languages of their respective countries. However, the SES of the children was not always provided. There was a subset of national and international studies that focused on immigrant populations, which typically involved children of lower SES and who spoke a minority language. SES is a factor to consider when studying DLL children, because research on monolingual children has shown that children from low-SES homes have lower vocabulary abilities and display different language abilities than children from middle-SES homes (Hart \& Risley, 1995; Hoff, 2003; Pan, Rowe, Singer, \& Snow, 2005). Because many DLL children grow up in low-SES homes, SES and bilingualism can be confounded in studies of children's development.

\section{Research Designs}

The studies employed a variety of research designs. Thirty-four (19\%) of the articles were case studies, with 21 of the studies focusing on infants/toddlers. Seventeen (9\%) were descriptive, meaning that no group comparisons were made, and 50 (28\%) were crosssectional. Fifteen $(8 \%)$ were correlational, meaning that relationships among variables were investigated. Sixteen (9\%) were experimental or quasi-experimental. Fifty $(27 \%)$ were longitudinal, with the majority of these having collected data at two points in time.

\section{Research Questions Addressed by the Studies}

The studies reviewed focused on a wide range of research questions. These included questions regarding the basic descriptive facts about the course of DLLs' development, the influence of environmental factors, and the relation between language and literacy development. In addition, the studies addressed theoretical questions about bilingualism, including the influence of dual language exposure on early speech perception, whether DLL children develop one or two language systems, and whether there is transfer of knowledge from one linguistic system to the other. Often, studies compared the development of DLL children to monolingual children, either directly or indirectly through the use of standardized tests normed on monolingual children. The reader is reminded that children learning two languages should not be expected to perform at the same level as monolinguals in all areas 
of language development, because DLL children are learning two linguistic systems (Hoff, Core, Place, Rumiche, Señor, \& Parra, 2012).

\section{Findings about Development}

Children's language development-The discussion of the literature published on dual language learners from birth through age five is organized around the following aspects of language: language processing (including behavioral and neurophysiological measures), vocabulary development, word learning processes, semantic development, oral comprehension, grammatical development, and pragmatic development. Also reviewed are studies that investigated code switching and transfer as well as factors that influence children's development.

Language processing-Three studies were categorized as investigations of language processing in DLLs. The first study examined the latency and location in the brain of the electrical activity evoked by the presentation of words to 19- to 22-month-old SpanishEnglish DLLs in their dominant and non-dominant languages (Conboy \& Mills, 2006). The findings revealed a faster speed of processing of known words as indicated by shorter latency of evoked response potential (ERP) relative to the latency of response to unknown words. This difference in processing speed occurred earlier in DLL children's dominant language than their non-dominant language. In addition, faster processing of known words was found for children who were more advanced on a composite language measure compared to children with less advanced language. It was also determined that the brain regions involved were different for children's dominant and non-dominant languages (Conboy \& Mills, 2006). These findings suggest that the organization of the brain for language processing and the speed of language processing may be different for DLL children's two languages if the children have more experience, and relatedly, more knowledge in one language than the other.

The second study provided additional evidence that DLLs are more efficient at processing the language they hear more and know better. In this study, children were presented with a familiar word aurally and shown two pictures, one of which corresponded to the word that was spoken. The time it took children for to look at the correct picture was then measured. Results showed that Spanish-English DLL toddlers (aged $21 / 2$ years) were faster at processing the language they heard more, and individual differences in speed of processing were related to vocabulary size within a language but not across languages (Marchman, Fernald, \& Hurtado, 2010).

The third study compared Turkish-English DLL and Turkish monolingual kindergarteners' abilities to process language, using tasks in Turkish. Monolingual children outperformed DLL children on six of the eight processing tasks; however, minimal information was provided about the language experiences of the DLL children. Additionally, the language processing tasks were not well described, making it difficult to interpret the findings presented in the study (Sevinç \& Önkol, 2009).

Phonological Development-Phonological development has received more attention than other areas of DLLs' language development. Studies focusing on infants/toddlers 
targeted children's speech sound discrimination abilities and early speech sound development. Most of these studies were conducted with populations outside the U.S. In contrast, the majority of investigations involving preschoolers focused on speech sound development and were conducted primarily with Spanish-English DLLs living in the United States.

The research focusing on infants finds no difference between DLLs and monolinguals in their ability to distinguish between two different languages. Specifically, Bosch and Sebastián-Gallés (2001) found no differences among Spanish monolingual infants, Catalan monolingual infants, and Spanish-Catalan DLL infants' abilities to discriminate Spanish from Catalan at four-months of age.

Definitive evidence has not been found as to whether or not differences exist in the developmental trajectories of monolingual and DLL infants' abilities to distinguish contrasting speech sounds within a language. It is well known that all infants begin life able to perceive essentially every sound contrast languages use, but by the age of six to twelve months (depending on the particular sound contrast) monolingual infants' speech perception has been "tuned" to their one language (Kuhl, Stevens, Hayahsi, Deguchi, Kiritani, \& Iverson, 2006; Werker \& Tees, 1984). This means that they discriminate sounds that are different phonemes in the ambient language, but they no longer discriminate between different sounds that do not mark a difference in meaning. Infants exposed to two languages are able to discriminate the sound contrasts of both their languages at the end of their first year. However, studies that focused on the course of development yield different results depending on: (a) the particular language pairs the infants hear, (b) the sound contrasts that are under study, and (c) the measure of discrimination used.

Some evidence suggests that DLL infants pass through an intermediary stage between having the newborn's ability to perceive essentially all contrasts and the tuning of perception to only the native language contrasts. During this intermediary stage, DLL infants appear not to discriminate between contrasts in one of their languages. This $\mathrm{U}$-shaped developmental pattern, one in which discrimination is evident at four months, not at eight months, and then reemerges at twelve months, has been found in more than one study (Bosch \& SebastiánGallés, 2003; Burns, Yoshida, Hill, \& Werker, 2007; Sundara, Polka, \& Molnar, 2008). For example, one study that used brain measures of phonetic discrimination (i.e., ERPs) found that Spanish-English DLL infants between 6- and 9-months of age did not show evidence of neural discrimination of Spanish or English contrasts that monolingual infants showed at that age. Evidence of neural discrimination of contrasts did not occur until 10- to 12-months of age in DLLs (Garcia-Sierra et al., 2011). It is thought that this U-shaped pattern may occur because children exposed to two languages require more time to accumulate sufficient data to discriminate the two sets of phonetic categories they must learn.

In contrast, other investigations have shown that DLL infants are able to maintain their abilities to discriminate sounds between 8- and 10-months of age and do not show the Ushaped pattern. One study that used a different behavioral method for testing infants' discrimination abilities found that 8-month-old Spanish-Catalan DLL infants could discriminate a specific vowel contrast, results not found in other studies (Albareda-Castellot, 
Pons, \& Sebastián-Gallés, 2011). Another study suggested that if the two languages a DLL infant hears are rhythmically different--as in Spanish and English, then DLL infants maintain their ability to differentiate different phonetic categories like monolinguals. Specifically, 8-month-old, Spanish-English DLL infants were able to discriminate a vowel contrast that exists only in English (Sundara \& Scutellaro, 2011). The authors of this study suggested that the rhythmic differences between Spanish and English allowed infants to tag the speech they heard as belonging to one or the other language, and thus the infants did not require any additional data to pull apart the properties of their input that arise from each language (Sundara \& Scutellaro, 2011).

Additionally, studies demonstrated that DLL infants' sensitivity to the phonotactic constraints (i.e., allowable syllable structures, and consonant clusters) of the target language(s) (Sebastián-Gallés \& Bosch, 2002) and sensitivity to vowel contrasts (RamonCasas, Swingley, Sebastián-Gallés, \& Bosch, 2009) may differ from monolinguals' in the non-dominant language. But on other tasks, DLL infants perform at levels that are not different from monolinguals' performance. For example, in one study, DLL infants showed preference for familiar words in both their languages at the same age as monolingual infants showed this preference (Vihman, Thierry, Lum, Keren-Portnoy, \& Martin, 2007). Another study of infant word learning found that DLL infants accommodate phonetic variation (i.e., variations in productions that might be associated with accented speech) better than monolingual infants (Mattock, Polka, Rvachew, \& Krehm, 2010; Ramon-Casas et al., 2009).

Studies that targeted children's production of speech sounds addressed a variety of research questions, including the presence of one or two phonological systems, the composition of children's phonetic (speech sound) inventories, and children's phonological accuracy and complexity. Many of the studies involved samples of 10 or fewer DLLs.

The vast preponderance of the evidence suggests that DLL infants/toddlers and preschoolers have two separate phonological systems, meaning that DLLs have different mental representations for each sound in their two languages (Anderson, 2004; Brice, Carson, \& O’Brien, 2009; Fabiano \& Goldstein, 2005; Fabiano-Smith \& Barlow, 2010; Fabiano-Smith \& Goldstein, 2010b; Gildersleeve-Neumann \& Wright, 2010; Gildersleeve-Neumann, Peña, Davis, \& Kester, 2009; Paradis, 2001; Simon, 2010). However, cross-linguistic effects are observed in children's speech sound productions, with some evidence suggesting that the dominant language has a great influence over the weaker language (Mok, 2011; Paradis, 2001). As children develop their speech sound abilities over time, these effects are observed less frequently (Fabiano-Smith \& Barlow, 2010; Gildersleeve-Neumann et al., 2009; Gildersleeve-Neumann \& Wright, 2010; Lin \& Johnson, 2010).

With regard to children's speech sound production, DLL infants/toddlers' speech sound development may be delayed in their less dominant language in comparison to monolinguals. For example, DLL infants/toddlers' vowel acquisition was delayed in their second language (L2) in comparison to monolinguals, although no differences were observed between DLLs' L1 vowel learning and monolinguals (Kehoe, 2002). Also, German-Spanish DLLs' voice-onset time was not clearly established by age two, the age where this was established in monolinguals (Kehoe, Lleó, \& Rakow, 2004). However, one 
study indicated that DLL infants/toddlers seem to have an advantage over monolinguals when learning more complex speech sound patterns (Kovács \& Mehler, 2009).

During the preschool years, DLL children catch up to their monolingual peers in their ability to produce speech sounds. Specifically, a case study of two Japanese-English DLLs found that the children's ability to differentiate the voice onset time for voiceless stops (/p/, /t/, /k/) in their two languages emerged as children developed (Johnson \& Wilson, 2002). Additionally, studies of DLL preschoolers' learning a variety of languages, including Spanish, Russian, Arabic, and Chinese and living in different countries demonstrated that DLL children's phonetic inventories (i.e., the range of speech sounds produced) are as complex as monolinguals during the preschool years (Fabiano-Smith \& Barlow, 2010; Gildersleeve-Neumann, Kester, Davis, \& Peña, 2008; Gildersleeve-Neumann \& Wright, 2010; Khattab, 2002; Lin \& Johnson, 2010). Sequential language learners, or children who began learning their second language after age three, appear to use their knowledge of their L1 to aid them in acquiring the phonological system of their L2 (Anderson, 2004).

In general, DLL preschoolers' accuracy of their speech sound productions (as measured by percent consonants produced correctly) is high in their two languages (Fabiano-Smith \& Goldstein, 2010a; Lin \& Johnson, 2010; MacLeod, Laukys, \& Rvachew, 2011). However, their phonological accuracy appears to be higher for sounds that are shared between their two languages than for sounds that are not shared (Fabiano-Smith \& Goldstein, 2010a).

Whether children's accuracy is higher in their first language (L1) or their second (L2) is unclear. A study by Anderson (2004) found that DLLs who spoke either Korean, French, or Russian and English had higher accuracy in their L1 than in English, their L2 (Anderson, 2004). The opposite was observed by Brice et al. (2009) whose results showed that children's accuracy in English, their L2, was higher than their L1. Brice and colleagues concluded that this finding might be due to the amount of English to which the children had been exposed. However, Fabiano-Smith and Goldstein (2010a) did not observe an impact of children's exposure to their languages on the accuracy of their speech sound production. Given the small sample sizes of these studies, a conclusion about the role of language exposure on children's speech sound development cannot be made at this time.

Studies also compared the speech sound accuracy and complexity of DLL and monolingual children. The findings were inconclusive. One investigation found that English monolinguals had higher speech sound accuracy and complexity as measured by PCC (percent consonants correct) and pMLU (a measure of word length and consonant accuracy) than Spanish-English DLL children (Bunta, Fabiano-Smith, Goldstein, \& Ingram, 2009). Another found no differences between Spanish-English DLL children and monolinguals, but found that Spanish monolinguals had higher PCCs than DLLs but not higher pMLUs (Fabiano-Smith \& Goldstein, 2010a).

In sum, the evidence is clear that infants exposed to two languages can discriminate one language from the other and can learn the sound contrasts used by both, although questions remain about their developmental trajectories. Additionally, DLL infants/toddlers show evidence of having two distinct phonological systems, although cross-linguistic influences 
may be observed, particularly in the speech of younger children. DLL infants/toddlers' speech sound production may not be equivalent to monolinguals in their less dominant language during their early years; however, DLL preschoolers appear to catch up to monolingual levels. Overall, it can be concluded that there are many similarities between DLL and monolingual children's speech sound development during the preschool years (Goldstein \& Washington, 2001).

Vocabulary Development-Studies of DLL children's vocabulary development investigated both vocabulary composition and size. Studies involving preschoolers compared the development of monolingual and DLL children, sequential and simultaneous learners, and older and younger children. The effect of school entry on children's development has also been studied. Most of the investigations discussed were conducted in the United States or Canada, with three conducted in Europe. Note that three classic studies published before 2000 were included in the discussion to provide needed background information.

Studies of vocabulary composition analyzed the distribution of infants/toddlers' vocabulary knowledge across different types of words (e.g., social function words, nouns, predicates, and closed class words). Specifically, four studies (Conboy \& Thal, 2006; David \& Wei, 2008; Holowka, Brosseau-Lapré, \& Petitto, 2002; Levey \& Cruz, 2003) and one classic study (Pearson, Fernández, Lewedeg, \& Oller, 1997) addressed this area. All found that DLL children showed distributions much like those described for monolingual Englishspeaking children. Additionally, the studies found that, as in monolingual English-speaking children, nouns dominate early vocabularies more than later vocabularies. For example, Mandarin Chinese-English DLL infants/toddlers produced significantly more nouns than verbs when their vocabularies in both languages were combined. In fact, out of the 100 words produced by all 17 DLLs in the study, 70 were nouns and 13 were verbs. This is in contrast to monolingual Chinese-speaking children who tended to produce more verbs than nouns (Levey \& Cruz, 2003). Moreover, DLL children produced nouns in both Chinese and English, but verbs were produced only in Chinese, suggesting that these verbs were produced in Chinese during adult-child interactions and pointing to the influence of adultchild interaction on language development.

When estimating DLLs' vocabulary knowledge combined across their two languages, DLL infants/toddlers were found to have the same rate of vocabulary growth as monolinguals from the ages of one and one-half years to three years (Pearson, Fenández, Lewedeg, \& Oller, 1997). In addition, DLL infants/toddlers' conceptual vocabularies (i.e., the number of vocabulary concepts known in their two languages combined) are the same size as monolinguals' vocabularies (Junker \& Stockman, 2002; Lundén \& Silvén, 2011; Pearson, Fernández, \& Oller, 1993), with some overlap in the words/concepts known in both languages. It has been suggested that the degree of overlap in young children's vocabularies may be greater when the children's two languages are typologically related, resulting in the similarity in forms of words across the two languages (Schelletter, 2002). Also, the overlap between DLL children's vocabularies supports the theory that children have two separate linguistic systems (Pearson, Fernández, \& Oller, 1995). That is, for many concepts, DLL children know two different words, one in each language. 
With regard to the size of DLL infants/toddlers' vocabularies in their individual languages, studies consistently found that DLLs have smaller vocabularies and slower rates of growth over time in each language when compared to monolinguals (Marchman et al., 2010; Place \& Hoff, 2011; Vagh, Pan, \& Mancilla-Martnez, 2009). However, many DLL infants/ toddlers have vocabulary sizes within the normal range of variation for monolingual children, particularly in their dominant language (cf. Pearson et al., 1993; Vagh et al., 2009). These findings give rise to some confusion in the literature. Some findings have been interpreted and widely cited as evidence that bilingualism has no effect on the development of each language, because DLL children's vocabularies can fall within the normal range of monolingual children (Pearson et al., 1993). As Bialystok (2001) has pointed out, however, the normal range of variation is wide. Further, reanalysis of Pearson et al.'s (1993) data showed that more of the DLL than monolingual children fell below the $10^{\text {th }}$ percentile with respect to monolingual norms (Bialystok, 2001). Our interpretation is that DLLs acquiring two languages take longer to build their vocabularies in each language than children who are acquiring only one language, but not so much longer as to necessarily be outside the normal range of variation in their stronger language.

Studies of preschoolers also show that DLL children's vocabularies in their individual languages are smaller than those of their monolingual peers. This finding is supported by Bialystok, Luk, Peets, and Yang (2009) who studied DLLs who were learning English and a variety of home languages (SES not specified) and Bialystok, Barac, Blaye, and PoulinDubois (2010) who studied middle-SES DLLs learning English and French. In both studies, DLLs, who lived in Canada, scored lower on the Peabody Picture Vocabulary Test -III than monolingual English speakers. The conclusion is also supported by the two studies of Spanish-English preschoolers living in the U.S from low-SES homes. Both found that DLL children scored two or more standard deviations below the English and Spanish norms on standardized vocabulary tests administered (Hammer, Lawrence, \& Miccio, 2008a; Tabors, Páez, \& López, 2003). It is important to note that the children in Hammer et al.'s investigation were enrolled in Head Start programs where English was the language of instruction, and thus came from homes of low-socioeconomic status (SES). The sample involved in Tabors et al.'s study also involved a large percentage of children from low-SES homes who attended English-speaking preschools.

Differences in vocabulary abilities, however, were identified between children who are simultaneous learners and sequential learners. Hammer and her colleagues (2008a) observed that simultaneous learners entered and exited Head Start programs with higher English vocabulary scores than sequential learners. The opposite pattern was found for children's Spanish vocabularies.

Bilingual children, however, appear to make gains relative to their monolingual peers over time. Hammer et al. (2008a) observed that both sequential and simultaneous learners' standardized vocabulary scores increased over their two years in Head Start. Simultaneous learners began Head Start with a below-average English vocabulary, and ended Head Start with a vocabulary within the lower end of the average range for monolingual speakers. Sequential learners' English vocabulary grew at a faster rate than simultaneous learners. Sequential learners also made gains on the monolingual norms in Spanish and developed at 
a faster rate than simultaneous learners, ending up in the average range for monolingual speakers of Spanish. Thus, both groups made gains on monolinguals in English over the two-year period and sequential learners also made gains in Spanish.

Two studies focused on preschoolers' development of their second language (L2) after school entry. A study of Dutch-Turkish DLLs living in the Netherlands showed that children's L2 vocabulary development accelerated when they entered school between the ages of three and four, but they did not catch up to monolingual peers by the end of the study (Leseman, 2000). However, Goldberg, Paradis, and Crago (2008) also observed that DLL children living in Canada, who spoke a variety of languages, caught up to monolinguals over time in English. Specifically, five-year-old DLL children from a variety of home language backgrounds and who lived in Canada caught up to monolingual norms of the PPVT-III after an average of 34 months of exposure to English. The studies of Goldberg et al. (2008) and Hammer et al. (2008a) demonstrate that DLL children can catch up to monolingual English children, but need time to do so.

Two studies compared the development of younger and older DLL children enrolled in preschool programs in the U.S., without reference to monolinguals (Kan \& Kohnert, 2005; Sheng, Lu, \& Kan, 2011). In one study, it was found that five-year-old children outperformed three-year-old children in English for both receptive and expressive vocabulary, but not in Hmong, indicating a relative stabilization of L1 skills, alongside more robust growth in L2. Additionally, the results showed that although there were no significant differences in performance between receptive and expressive vocabulary in English, receptive scores were significantly higher than expressive scores in Hmong for both age groups. Moreover, younger children showed no L1-L2 difference on expressive vocabulary, but older children's performance on this same task was significantly greater in English. The authors suggested that a shift from relative L1 to L2 "dominance" may be under way after an average of only 20 months in the early educational setting.

The second study found similar results in that younger and older groups of MandarinEnglish speaking DLLs had larger vocabularies in English than Mandarin. In addition, the children showed significant increases in English vocabulary, but minimal gains in Mandarin. Receptive-expressive gaps in vocabularies were noted, with differences being greater in Mandarin (Sheng et al., 2011).

Another study investigated the English vocabulary development of over 1,200 DLLs during one year in preschool using the Individual Growth and Development Indicators (IGDI) for picture naming. The growth of children who spoke Somali, Spanish, and English were compared. Results revealed the DLLs who spoke Somali had greater vocabulary growth than children who spoke the other two languages; however, factors that may have contributed to this difference were not investigated (Estrem, 2011).

In summary, the findings in the literature concur that during infancy, DLL children, as a group, lag behind monolingual children in vocabulary growth in each of their languages. However, their conceptual vocabularies are within the typical limits of monolingual children during infancy. The picture these data present is one in which DLL children proceed along 
the same path in building lexicons in each of their languages as monolingual children. The children may proceed at a different pace in each language, but the composition of the lexicons in each language is a function of where in the path the child is (as the composition of children's vocabularies changes over time), rather than being a function of the children's age or the children's total lexical knowledge across both languages.

During the preschool years, DLL children's vocabularies appear to be lower than those of their monolingual peers in their individual languages; however, it should be recalled that the studies in this area were conducted primarily on children from low-SES homes and who attend preschools where their L2 is the language of instruction. There is some evidence that DLL children catch up to monolinguals over time, as suggested by Cummins (1981). Also, there appear to be differences between sequential and simultaneous learners' development and differences in the vocabulary abilities of younger and older children, with a shift in dominance to the children's L2 occurring over time.

Word learning processes-Four studies were identified that examined word learning processes in young DLL children. Two studies examined infant/toddler word learning using the switch task. In this task, novel words are paired with pictures of novel objects until the child habituates, and then recovery from habituation is measured in response to when the pairing of objects and words is switched. One study found DLLs use relevant language sounds to direct word learning developmentally later than monolinguals (Fennell, ByersHeinlein, \& Werker, 2007). This study tested whether 14- to 20-month-old DLLs could learn minimally different words (e.g. bih and dih). The DLL sample included a heterogeneous sample of children who were exposed to English and another language and two homogeneous samples of English-Chinese and English-French children residing in Canada. These DLLs did not learn these similar-sounding words until 20 months, whereas monolingual infants/toddlers succeed at this task at the age of 17 months. The authors hypothesized that this difference between DLL and monolingual children may be due to the increased cognitive load of learning two languages. However, another study comparing English-French DLL children to English and French monolinguals found that the DLLs performed better than the monolinguals and were successful in word learning at 17 months, as measured by the switch task, provided the phonological properties of the syllables to be learned were consistent with their DLL experience (Mattock et al., 2010).

Two studies examined older DLL children's fast mapping abilities (i.e., the ability to learn a word after a limited number of exposures). In one study, German-English DLLs living in Germany were better at fast mapping in their L1 than in their second language, English. Although a second study of Hmong-English DLLs in the U.S. showed that children did slightly better in L1 (Hmong) than L2 (English) on the fast mapping tasks, the differences were not significant. The authors explained that this could be due to the large amount of individual variation in performance along with the limited number of fast mapping trials (Kan \& Kohnert, 2008). Unlike past findings with monolingual children, there was no effect of age on the fast mapping tasks. Although no relationships were found between existing vocabulary knowledge and fast mapping in the children's LI, Hmong, or the children's L2, English, in this latter study, there were statistically significant relationships between vocabulary knowledge and fast mapping across the two languages. English expressive fast 
mapping was negatively correlated with Hmong vocabulary knowledge, which the authors interpreted as suggesting a temporary cross-linguistic interference (Kan \& Kohnert, 2008). Based on the studies that have been conducted, it is unclear if DLL children are better at fast mapping in their first language as compared to their second language.

Semantic development-Two studies targeted DLL children's semantic development. One case study that followed a child from 18 to 36 months of age examined whether vocabulary development in DLLs is affected when the conceptual distinctions that are lexicalized in one language are not in the other (Silva-Corvalán \& Montanari, 2008). The example studied is the acquisition of the verb to be in English and the acquisition of ser and estar, in Spanish. Ser and estar are both translated as to be, but they are not interchangeable. Roughly, ser is used in reference to essential characteristics and permanent states (El es un hombre-He is a man) and estar refers to location and temporary states (El está en la sala-He is in the living room). The author concluded that the child learned to distinguish the constructions that required each form in Spanish without difficulty and suggested that this was because each was learned directly from input—as opposed to acquisition being conceptually driven.

Another study was identified that investigated semantic development during the preschool years (Sheng, McGregor, \& Marian, 2006). This study compared five- to eight-year old Mandarin-English DLL children's ability to produce word associations in their two languages and in relation to age-matched monolingual children's word association abilities. The results suggested parallel development in DLLs' L1 and L2 lexical-semantic skills. Paradigmatic performance, or the ability to associate words within a language, was similar in L1 and L2, and the results showed that paradigmatic responding correlated the most for L1 and L2 nouns, and the least for verbs, suggesting that word associations for nouns proceed in a more similar manner across languages than for verbs. In addition, both monolingual and DLL groups achieved similar paradigmatic performance in the English word association test. Also, there was a DLL advantage for verbs, with more DLLs responding paradigmatically than monolinguals.

Given the limited number of studies in this area, it is difficult to draw firm conclusions. Clearly more research is needed to answer the question of how bilingualism shapes children's lexical-semantic organization.

Oral Comprehension-Minimal attention has been paid to young DLL children's comprehension of their two languages. Only two articles were identified. Both of these articles were from Hammer, Lawrence, and Miccio's (2008a, 2008b) longitudinal investigation of DLL Head Start children. The first focused on simultaneous and sequential learners' growth in oral comprehension during the children's two years in Head Start. Similar to children's vocabulary abilities, simultaneous learners began and ended Head Start with higher English comprehension, and sequential learners had consistently higher Spanish comprehension. Both groups' abilities to comprehend Spanish and English were below monolingual norms at the beginning of Head Start. The groups' English abilities increased over the two-year period, with simultaneous learners' scoring within the typical monolingual range by the end of Head Start. The two groups' Spanish abilities increased initially but then 
decreased during their time in Head Start classrooms where English was the language of instruction, indicating that their development was not keeping up with the monolingual norms (Hammer et al., 2008a).

The second study investigated the effect of summer vacation on DLL children's oral comprehension development (Hammer et al., 2008b). Children were divided into groups depending upon whether their scores increased or decreased during two years. The results showed that summer vacation had a differential effect on children's comprehension. Children whose scores increased during their two years in preschool experienced decreases in their comprehension over the summer whereas as children whose scores decreased during preschool experienced increased scores during the summer months.

Grammatical development-Studies of DLL children's early grammatical development during infancy focused on determining if children learning two languages simultaneously from birth have two separate language systems, with most of these being case studies. Other studies targeted DLL children's morpho-syntactic development, fluency, and metalinguistic awareness of grammatical constructions.

Based on nine case studies involving DLL infants/toddlers living in a variety of countries including the U.S., DLL children have two separate grammatical systems. This conclusion is supported by investigations that examined the phenomenon of subject realization. These studies found that DLL children had no difficulty learning the grammatical rules of their two languages when one of their languages did not require the subject to be expressed (e.g., Spanish, Italian, and Catalan) and their other language required an explicit subject (e.g., English) (Juan-Garau \& Perez-Vidal, 2000; Paradis \& Navarro, 2003; Serratrice, 2002; Serratrice, Sorace, \& Paoli, 2004; Silva-Corvalán, 2007). Support for the conclusion that DLL children have two separate systems was also provided by a study that showed that a Spanish-English DLL child used different aspectual markers for the two languages that the child was learning (Castro \& Gavruseva, 2003) and by another study that showed Japanese DLL children learned the linguistic devices for formulating questions in their two languages (Mishina-Mori, 2005).

Six studies investigated DLLs development of morphology and/or syntax, with four studies being conducted in Australia, Germany, France, and Canada. In general, the studies found that DLLs' abilities to produce morphological and syntactic targets were less accurate than monolinguals, but that DLLs' generally followed the same pattern of development as monolinguals (Bland-Stewart \& Fitzgerald, 2001; Bonnesen \& Chilla, 2011; Nicholls, Eadie, \& Reilly, 2011; Nicoladis \& Marchak, 2011; Paradis, Nicoladis, Crago, \& Genesee, 2010). Also, it was concluded that difference in the amount of input that DLLs receive in their individual languages explained the differences between DLLs and monolinguals accuracy in producing various grammatical structures (Bonnesen \& Chilla, 2011; Nicholls et al., 2011; Paradis et al., 2010).

In addition to studying morphological development, one study investigated DLL children's fluency, as measured by their production of grammatical revisions (Bedore, Fiestas, Peña, \& Nagy, 2006). Four- to six-year-old Spanish-English DLLs' expressive language was 
compared to the expressive language of their functionally monolingual peers. No differences were observed between the two groups in terms of the percentage of grammatical revisions produced or revision strategies used. Children's revisions were related to their language productivity as measured by mean length of utterance and the number of words produced. The authors concluded that DLLs do not have greater linguistic uncertainty than monolinguals.

Two studies focused on comparing the metalinguistic abilities of DLLs and monolinguals through tasks that required children to identify grammatically correct utterances. Using a sample of children ranging from two- to six-years in age, Foursha-Stevenson and Nicoladis (2011) found that French-English DLLs had better syntactic awareness than their monolingual peers. Similarly, Davidson, Raschke, and Pervez (2010) found that five- and six-year-old DLLs, who spoke Urdu and English, were better at identifying grammatically incorrect utterances than their Urdu- and English-speaking monolingual peers. In contrast, three- and four-year old DLLs outperformed their monolingual peers who spoke Urdu but not their monolingual peers who spoke English. Thus, the finding suggested that DLLs may have an advantage over monolinguals in metalinguistic awareness as their language abilities develop.

In summary, the studies reviewed on children's grammatical development paint a picture of DLL children proceeding down two relatively independent paths of development in acquiring two languages, similar to the evidence presented on children's phonological and vocabulary development. In comparison to monolinguals, DLL children appear to be acquiring morpho-syntactic structures in the same general order as monolinguals, although DLLs' accuracy is less than their monolingual peers. More studies, however, are needed in this area. Also, it appears that DLLs may have an advantage over monolinguals in their metalinguistic awareness, although more evidence is needed before a firm conclusion can be made.

Pragmatic Development-Five studies were identified that focused on children's pragmatic development, with three involving children living outside of the United States. Two of the studies investigated children's abilities to repair communicative breakdowns. The results of one of these studies demonstrated that young French-English DLLs were able to repair communicative breakdowns by matching the language of the adults with whom they were interacting. However, when the language being spoken was not the reason for the communicative breakdown, children did not change languages when attempting to repair their message (Comeau, Genesee, \& Mendelson, 2007). The second study found no differences between young DLL and monolingual children's abilities to repair conversational breakdowns.

The remaining studies addressed different research questions. One case study showed that a young DLL had learned the pragmatic functions described by Halliday early in life (Keshavarz, 2001). The child, who was learning Farsi and English, showed independent use of the pragmatic categories in both languages, providing further evidence that DLL children have two separate systems. Another study found that DLL preschoolers were better at using tone of voice to judge the emotion of a speaker than monolinguals (Yow \& Markman, 
2011). The final study found that unlike their parents, 3- and 4-year-old DLLs did not adjust their language to the language of a third-party when engaged in a conversation. Children tended to use English, which was the language of their schooling (Tare \& Gelman, 2011).

Code switching-Code switching is a phenomenon that is observed in the language usage of DLL children and adults. It is thought to be a result of the interaction of two independent linguistic systems (Bernardini \& Schlyter, 2004; Cantone \& Muller, 2008). Relatively few studies have investigated young DLL children's code switching. Those that were conducted focused on preschoolers and populations outside the United States. These few studies showed that DLL children adhere to adult-like structural constraints in most of their code switching. This implies that they have complex knowledge of how to fit their two languages together in one utterance during production and that they possess language-specific syntactic knowledge early on (Paradis, Nicoladis, \& Genesee, 2000).

The studies also demonstrate that code switching is affected by language dominance (Bernardini \& Schlyter, 2004; Dahl, Rice, Steffensen, \& Amundsen, 2010; Jisa, 2000; Paradis \& Nicoladis, 2007). Bernardini and Schlyter (2004) found that in nearly all mixed utterances produced by three young Swedish-Italian and Swedish-French DLL infants/ toddlers, the stronger language filled in the gaps of the weaker language. The authors presented this as the Ivy Hypothesis, where the weaker language grew "like ivy on the structural tree of the stronger language" (p. 49). Other studies have also found code switching to serve as a compensatory strategy when DLL children do not know the target word in one language (Wei \& Lee, 2001). Wei and Lee found that when examining the knowledge of Cantonese classifiers among British-born Chinese children, many of the children code-switched from Cantonese to English when they did not know the word in Cantonese.

Several studies found that the role and patterns of language dominance vary by age and level of language production in the stronger language (Jisa, 2000; Paradis \& Nicoladis, 2007). Very preliminary evidence indicates that the age when the DLL child begins to produce his/her weaker language has an impact on the type and frequency of code switching (Jisa, 2000). Specifically, Jisa found differences between two DLL siblings, who were both French-dominant and raised in a bilingual household with a French-speaking father and an English-speaking mother from birth. The older sister (aged 3;6), who had more advanced grammatical development in her stronger language than her younger sibling (aged 2;3), replaced French grammatical functors with equivalent English functors more quickly than her younger sibling (aged 2;3). The older sister also showed more sensitivity to the language of her addressee than her younger sister.

Other studies have also found that DLL preschoolers are able to use their two languages appropriately depending on the situation, but whether they did so depended on their language dominance and their sensitivity to the DLL speech patterns of the greater community (Dahl et al., 2010; Kyratzis, 2010; Paradis \& Nicoladis, 2007). Another study found a relation between parental discourse strategies and a DLL child's rate of code switching. Specifically, a- 2-year-old Mandarin-English DLL child code switched more with her father than her mother. Her father accepted more code switching, whereas her mother 
expected that the child speak in one language (Min, 2011). Additionally, it has been found that code switching serves communication purposes and occurs very little when the DLL child talks with no communicative partner present (Dolitsky, 2000).

There is also evidence that some characteristics of code switching are language-specific, whereas other code-switching behaviors are similar across languages (Bader \& Minnis, 2000). Examining the speech of an Arabic-English child living in Jordan, Bader and Minnis (2000) found that some characteristics of the child's code-switching behavior, such as attaching affixes from one language to verbal or nominal stems from the other, mixing definite and indefinite articles, deleting the copulative $b e$, and switches related to word order, were found in other DLLs such as French-English, Spanish-English, and DutchEnglish children. However, unique characteristics of the Arabic-English DLL were also found.

Transfer-Several studies examined relations between the components of the children's two languages and how children's abilities might transfer across the two languages. These studies targeted a variety of research questions including the associations between lexical and grammatical development, the nature of cross-linguistic influences, and the direction of transfer.

The associations between lexical and grammatical development were addressed by two larger-scale studies of Spanish-English DLL toddlers ranging in age from 18 to 30 months of age (Conboy \& Thal, 2006; Marchman, Martínez-Sussman, \& Dale, 2004). Both studies found that lexical and grammatical development were related within each language, as they are in monolingual development, but lexical and grammatical development were not related across languages. In Conboy and Thal's study, Spanish-English DLL toddlers acquired predicate and closed class words for each language at levels predicted for their vocabulary size in each respective language. The use of grammatical terms and complexity of language were related more strongly to same-language vocabulary development than to broader lexical-conceptual development across languages. Marchman et al. (2004) also found that within-language vocabulary-grammar relationships were stronger than cross-language relationships with Spanish-English DLL toddlers. Similarly, Parra, Hoff, and Core (2011) found significant language-specific relations in 2-year-old Spanish-English DLLs among the phonological accuracy of the children's nonword repetition, their productive vocabulary size, and the grammatical complexity of their speech.

Two studies examined the relationships between specific components of children's two languages in older children. Kan and Kohnert (2008) found a significant positive relationships between receptive and expressive vocabulary in both Hmong and English, as well as positive cross-linguistic relationships between receptive vocabulary in Hmong and expressive vocabulary in English within three- to five-year-old Hmong-speaking DLLs. This suggests that preschoolers who understood more Hmong words were more likely to know more words in English. Tabors et al. (2003), however, found a small negative relationship between DLL preschoolers' Spanish and English expressive vocabularies. They did find positive relationships between Spanish and English on other early literacy and oral proficiency measures such as letter-identification skills and memory for sentences. The 
reason for the differences between Tabors et al.'s findings and Kan and Kohnert's findings on vocabulary may be due to the fact that Kan and Kohnert's children attended a bilingual preschool program whereas Tabors et al.'s children attended an English-speaking preschool program. Given that both studies had large individual variation on the measures, and that there were only two studies on this topic, more exploration is necessary to understand the complex relationships between the two languages of DLL children.

Other studies examined whether cross-linguistic influences may be specific to the language structure examined or influenced by the dominant language (Kupisch, 2007; Paradis, 2001; Yip \& Matthews, 2000; Zwanziger, Allen, \& Genesee, 2005). For example, Zwanziger et al. (2005) found no evidence of crosslinguistic influence on morpho-syntax from English to Inuktitut or Inuktitut to English. However, other studies found considerable interactions between DLL children's two languages, resulting in a developmental profile that is quite unlike monolingual children's (Paradis, 2001; Yip \& Matthews, 2000). Transfer from the dominant language, Cantonese, to the weaker language, English, was evident in the syntactic development (wh-in-situ interrogatives, null objects, and pronominal relatives) of a Cantonese-English DLL child in Hong Kong (Yip \& Matthews, 2000). In another study with a French-English two-year-old child, Paradis (2001) also found that French-dominant DLLs, but not English-dominant DLLs, had a stronger tendency to treat English words like French words, suggesting that language dominance may be responsible for the directionality of cross-linguistic effects in phonological systems.

Although language dominance may serve as a determinant of unidirectional transfer (Paradis, 2001; Yip \& Matthews, 2000), other studies have pointed out that properties of the target language and input ambiguity also play a role in the transfer effects (Kupisch, 2007; Yip \& Matthews, 2000). Kupisch suggested that transfer in a particular domain might occur only if the dominant language has language-internal properties that promote the acquisition of a particular domain. If the dominant language is not beneficial to the acquisition of that grammatical domain, then transfer does not happen. Additionally, Yip and Matthew discuss Müller's (1998) study where transfer may occur when two different grammatical hypotheses are compatible in one language (input ambiguity) regardless of language dominance. In Müller's study, German was the target of transfer regardless of whether it was the dominant language for German-English DLLs for verb-object order in subordinate clauses. This was due to the fact that German allows both verb-object and object-verb order, while English has fixed verb-object order. As such, no transfer from German to English was expected regardless of language dominance. Moreover, in a later study, Müller and Hulk (2001) provide further evidence that it is not language dominance that promotes crosslinguistic syntactic influence in Dutch-French, German-French, and German-Italian DLL children, but that it is the grammatical properties of a language that determine when and where transfer occurs.

Two studies reported that transfer is bi-directional (Foroodi-Nejad \& Paradis, 2009; Gu, 2010). Foroodi-Nejad and Paradis found both English influence on Persian and Persian influence on English in the Persian-English DLLs' production of novel compound words. These results showed partial evidence for the structural overlap hypothesis, where crosslinguistic influence occurs when there is structural overlap between the two languages, 
and partial evidence for the language dominance hypothesis. $\mathrm{Gu}$ (2010) also found bidirectional crosslinguistic influences with Cantonese-English DLLs. Crosslinguistic influences were seen in English prepositional datives and Cantonese inverted double object datives, two domains that were also difficult for monolingual children. Transfer effects were due to language dominance and input ambiguity.

As structural overlap between the two languages (French and English) and language ambiguity did not completely explain the cross-linguistic transfer of adjective placement among French-English DLLs, Nicoladis (2006) proposed to consider cross-linguistic transfer as a manifestation of speech production errors. When there were two syntactic rules in one language (e.g. adjective noun strings in French where both adjective-noun and nounadjective order are allowed, versus only adjective-noun order in English), results showed that children not only reversed more adjective-noun strings in French as predicted by the overall/ambiguity hypothesis, but they also reversed more adjective-noun strings in English than monolinguals. More studies need to examine this idea that cross-linguistic transfer is an "epiphenomenon of speech production."

In general, these studies demonstrate that factors such as language dominance and languageinternal properties may influence the transfer of children's abilities across languages.

However, additional studies are clearly needed in this area. The small number of studies on a given research question and the discrepancies in findings make it difficult to draw firm conclusions about transfer.

Factors that influence DLLs' development-Studies have also investigated factors that influence DLLs' language development. Most of these focused on the language input children received. Two also examined the role of children's language usage. One study investigated the relationship between child characteristics and language abilities. Others examined the role of parental responsivity and vocabulary development and children's attachment to their parents and teachers. Another group of studies examined the role that the home literacy environment and television play. Most participants in these studies were Spanish-English DLLs, some from low-income homes and some from high SES homes in the U.S.

During infancy, studies on children's language exposure found that DLLs' vocabulary size and grammatical abilities in each language are related to the children's relative amount of exposure to each language (Blom, 2010; Marchman \& Martínez-Sussman, 2002; Parra et al., 2011; Pearson et al., 1997; Place \& Hoff, 2011; Scheele, Leseman, \& Mayo, 2010; Vagh et al., 2009). Estimates of the variance in English (L2) and Spanish (L1) vocabularies were accounted for by the relative amount of exposure to each range from $10 \%$ to $49 \%$, from birth through age three (Marchman \& Martínez-Sussman, 2002; Patterson, 2002; Place \& Hoff, 2011). DLL infants/toddlers who hear and/or use relatively more English than Spanish have English vocabulary sizes that are more similar to monolingual English-speaking infants/ toddlers than do DLL infants/toddlers who hear and/or use relatively more Spanish than English (Vagh et al., 2009). DLLs with approximately balanced English and Spanish exposure and/or use score somewhere in between the English-dominant and Spanishdominant groups in their English language skills (Vagh et al., 2009). These findings are also 
supported by a study involving Moroccan (Tarifit-Berber) Dutch and Turkish bilingual children who were three years of age. This study found that differences in the patterns of language exposure largely explain differences in children's abilities in their two languages (Scheele et al., 2010).

There is preliminary evidence that the relative amount of exposure also predicts individual differences in DLLs' phonological accuracy in nonword repetition tasks. Among SpanishEnglish DLL 2-year-olds, accuracy of repeating Spanish-like and English-like nonwords was significantly related to the children's relative amount of exposure to Spanish and English (Parra et al., 2011).

In addition, one study has shown that DLL infants/toddlers' development is affected by whether or not parents are native speakers. Specifically, Place and Hoff (2011) found that two-year-olds' language abilities in their two languages varied as function of whether the children's mother, father, or both parents were native Spanish speakers. Children with a native English-speaking mother (and native Spanish-speaking father) were the most advanced in English. Children with two native Spanish-speaking parents were the most advanced in Spanish. Note that these children were the only children who were Spanish dominant. Children with a native Spanish-speaking mother and native English-speaking father scored between the other two groups of children. These differences in children's language abilities based on parental language background were fully mediated by home language use. This study also found that the amount of language mixing children experienced in these environments had no effect on their language development. This finding runs contrary to the widely held belief that DLL children are helped if their two languages are kept separate in their experience (Goodz, 1989; Pearson, 2008).

During the preschool years, significant relations have been found between the amount of exposure and children's vocabulary, similar to research on infants/toddlers (Quiroz, Snow, $\&$ Zhao, 2010; Thordardottir, 2011). However, preliminary evidence suggests that the amount of exposure to a particular language may or may not have an effect on DLLs' vocabulary growth over time. Specifically, one study examined mothers' reported usage of Spanish and English to their children during their children's two years in Head Start and kindergarten programs that were primarily English-speaking (Hammer, Davison, Lawrence, \& Miccio, 2009). In general, mothers increased their usage of English over time; however, changes in maternal language usage from "all/more Spanish than English" to "equal Spanish and English" or "more/all English" had no impact on children's English vocabulary growth during this period. Neither did mothers' continued use of Spanish. (Note that differences were not found for sequential or simultaneous learners.) It was suggested that children had sufficient exposure to English at school and the community that maternal usage of English did not accelerate children's English language development. Similarly, Mancilla-Martinez and Lesaux (2011a) found that Spanish usage in the home did not negatively impact DLLs' English vocabulary growth.

The opposite was true for children's Spanish vocabulary development. Mothers' increased usage of English over time had a negative impact on children's Spanish vocabulary development. Children whose mothers used increasingly more English had slower Spanish 
vocabulary growth. Children whose mothers continued to use Spanish had faster Spanish vocabulary growth. This is not surprising as the children's homes were the primary source of support for children's Spanish language development, given that English was the language of instruction. Thus, usage of Spanish in the home was needed to enhance children's Spanish vocabulary development.

Another study investigated the relation between children's exposure to English by their preschool teacher and children's vocabulary development (Bowers \& Vasilyeva, 2011). The results revealed that the total number of words (i.e. tokens) the teacher produced was related to vocabulary growth, whereas the number of words per sentence produced by the teacher had a negative effect on vocabulary growth.

Two studies included preschoolers' language usage as a key factor. The first investigation found that parental estimates of children's usage of their two languages predicted DLL children's abilities to produce speech sounds in their two languages (Goldstein, Bunta, Lange, Rodriguez, \& Burrows, 2010). The second study examined the role of children's usage of their two languages as well as the role of language exposure and specific demographic factors (Bohman, Bedore, Peña, Medez-Perez, \& Gillam, 2010). Specifically, Bohman et al. (2010) investigated the role these factors played in Spanish-English preschool and kindergarten children's semantic and syntactic abilities. The results showed that different factors predicted DLL children's outcomes in their two languages. Maternal education played a role in children's English semantic abilities and family income played a role in English semantics and Spanish semantics and syntax. The most significant finding was that children's language usage along with language exposure played a larger role in both children's English and Spanish language development than language exposure alone. Traditionally, attention has been placed on children's language exposure with minimal or no attention paid to their language usage. Bohman and his colleagues suggested that one explanation for this finding is that "using a language (i.e., output) forces the learner to process the language in a way that only hearing it (i.e., input) does not" (p. 339).

Other studies looked at children's characteristics as well as the role of acculturation and children's attachment relationships. Specifically, a negative relation was found between shyness-anxiousness and children's English receptive vocabulary development over a 6month period; however, this relation was mediated by the children's communicative competence, as defined as the children's ability to understand and use language and to participate in conversations (Strand, Pula, Parks, \& Cerna, 2011). A different study found that children from families who were highly acculturated had higher English language abilities than children from families who were bicultural or had low acculturation (OadesSese \& Li, 2011). This study also found that children's attachment to their mothers and warm and affectionate relationships with their teachers were related to higher English language abilities. In fact, children's relationships with their teachers contributed to higher language abilities above and beyond parental attachment.

Additionally, four studies addressed the role of the home literacy environment on DLL children's language development. All found relationships between parental literacy practices in their children's L2 (as measured by either frequency of book reading or library usage) and 
children's language outcomes in their second language (González \& Uhing, 2008; Kalia, 2007; Patterson, 2002). However, the study by Farver, Xu, Eppe, and Lonigan (2006) found that the relationship between parental literacy activities and language outcomes was mediated by children's interest in reading.

In addition to investigating the role of the home literacy environment, one study examined the role of television viewing on DLL infants/toddlers' vocabulary development. This study concluded that television viewing had no effect on DLLs' vocabularies in either language (Patterson, 2002).

In general, the findings from studies discussed in this section suggest that DLLs' abilities in their two languages are impacted by the amount of language exposure they received during the infant/toddler and preschool years. As preschool Spanish-English DLL children enter the school system, preliminary evidence suggests usage of Spanish at home is needed to support children's development of this language. Also, there is preliminary evidence that children's language usage plays an important role in their development of their two languages. Studies of the home literacy environment suggest that children's literacy experiences in their second language are related to children's language abilities in their second language.

\section{Children's Literacy Development}

The study of young DLL children's literacy development has received less attention than children's language development. The studies identified through the review focused on children's phonological awareness, emergent literacy, emergent writing, the relationship between oral language and literacy outcomes and the home literacy environment. Most of these studies were conducted on U.S. populations.

Phonological awareness-Studies which involved both preschool and kindergarten DLL children found that phonological awareness skills are related across languages and appear to transfer between languages (Anthony et al., 2009; Dickinson, McCabe, ClarkChiarelli, \& Wolf, 2004; Kim, 2009; López \& Greenfield, 2004; Tabors, Páez, \& López, 2003). This suggests that there is an underlying ability to manipulate and segment the sounds of language that can transfer from one language to the other. These findings are consistent with those of studies conducted on older DLL children (Durgunoğlu, Nagy, \& Hancin-Bhatt, 1993).

Less clear, however, are the factors that might facilitate or constrain DLLs' ability to develop phonological awareness skills, and the aspects of phonological awareness that are more susceptible to being transferred. One factor of particular relevance for DLL children's phonological development is vocabulary development. As children acquire more vocabulary, they become increasingly better at distinguishing phonemes, and therefore, at phonological awareness (Walley, Metsala, \& Garlock, 2003). Two studies examined the role of vocabulary in English and Spanish in the development of bilingual phonological awareness. In one of the studies, the results showed that vocabulary development in Spanish was a significant predictor of phonological awareness abilities in both English and Spanish (Anthony et al., 2009), whereas in the other, only English receptive vocabulary growth during preschool was predictive of English phonological awareness abilities in kindergarten 
(Scarpino, Lawrence, Davison, \& Hammer, 2011). Discrepancies in these findings might be explained by differences in the vocabulary measures used. Anthony et al. (2009) used an expressive vocabulary test whereas Scarpino et al. (2011) used a receptive vocabulary measure. As suggested by Scarpino et al., it might be possible that expressive vocabulary tests are better measures of children's vocabulary development so that cross-linguistic relationships can be found between vocabulary and phonological awareness.

Another factor is the influence of language exposure and proficiency. In a study of KoreanEnglish DLL kindergarteners, Kim (2009) found differences in children's phonological awareness depending on their experience with English. Children with higher proficiency in Korean than in English had phonological awareness levels consistent with those of Korean monolingual children. For example, children in this group found the onset-rime unit predominant in Korean, more accessible than the onset-rime unit more prevalent in English. In contrast, those children who had more extensive exposure to English did not show a difference in their performances on the onset-rime and rime awareness tasks, suggesting that their phonological representations were influenced by both languages' phonological structures.

Other studies investigated whether young DLL children have an advantage over monolingual children in their phonological awareness. The evidence from these studies is mixed. One study compared the phonological awareness of 5- and 6-year-old MandarinEnglish DLL children and of monolinguals who either spoke Mandarin or English (Marinova-Todd, Zaho, \& Bernhardt, 2010). The results identified a bilingual advantage in phonological awareness skills. Specifically, a significant advantage in phonological awareness skills for the DLLs was found not only in their stronger language (Mandarin) but also in their weaker language (English). However, Loizou and Stewart (2003) found that English-Greek DLLs outperformed English monolinguals on phonological awareness tasks, but Greek-English DLLs did not. The authors interpreted their findings as showing that DLLs are at an advantage over monolinguals when the second language was phonologically simpler than their first language.

Studies by Loizou and Stuart (2003) and Anthony et al. (2011) demonstrated that the relationship of phonological awareness between languages might vary depending on the phonological structure of the languages involved. Two studies conducted on populations living outside the U.S. suggest that there are both universal and language-specific constraints on the development of phonemic awareness (Laurent \& Martinot, 2009; SaieghHaddad, Kogan, \& Walters, 2010). For example, word length (i.e. long multisyllabic words are more difficult for children to analyze than shorter words) is a universal constraint, whereas phoneme position (i.e. initial versus final) seems to be dependent on the phonological structure of the language (Saiegh-Haddad et al., 2010).

Thus, the work conducted on DLLs' phonological awareness shows that children's abilities may transfer between their two languages and that there are factors such as vocabulary, language proficiency and exposure, and phonological characteristics of the languages, that might influence this transfer. Evidence is mixed as to whether preschool DLLs are at an 
advantage over monolinguals in phonological awareness, given their exposure to two languages. Clearly, more work is needed in this area.

Emergent literacy—Little information about DLL children's emergent literacy development was found in the studies reviewed. Two studies showed that Spanish-English DLL preschoolers performed below their monolingual peers in letter-word identification and overall emergent literacy during the preschool years in English and Spanish (Hammer, Miccio, \& Wagstaff, 2003; Páez, Tabors, \& Lopez, 2007). Another study found a small positive relationship between children's abilities to identify letters and words in Spanish and English (Tabors et al., 2004).

Furthermore, the studies indicated that DLLs perform better on standardized tests of emergent literacy than oral language (Hammer, Lawrence, \& Miccio, 2007; MancillaMartínez \& Lesaux, 2011b; Páez et al., 2007; Rinaldi \& Páez, 2008). A follow-up investigation of children who spent two years in Head Start where English was the language of instruction showed that DLL children's English letter word identification and emergent literacy abilities in English were at the monolingual norm in kindergarten. Further, children's Spanish letter-identification abilities were not as well advanced; however, children did not receive literacy instruction in Spanish (Hammer et al., 2007). These results are similar to a study of Samoan/Tongan-English DLLs living in New Zealand. The findings showed that children's early literacy abilities in their L1 declined when they transitioned into an English-only school (Tagoilelagi-LeotaGlynn, McNaughton, MacDonald, \& Farry, 2005).

In general, it appears that DLL children perform below monolinguals in emergent literacy during the preschool years, but may catch up to monolinguals in their L2 (English) in early grades when the focus is on decoding. DLL children's early reading abilities in their L1 seem to decline when they are schooled in their L2.

Emergent writing-Six studies examined emergent writing development of DLL children. Studies suggest that DLL children follow a similar developmental progression to monolingual children and recognize that their two writing systems are separate (Buckwalter \& Gloria Lo, 2002) and that children learn the form and function of written language over time (Reyes, 2006; Yaden \& Tardibuono, 2004). Another study showed a small positive relationship between Spanish-English DLL children's writing abilities as measured by a dictation task (Tabors et al., 2004). Some evidence suggests that DLLs who speak a variety of home languages can perform higher than monolinguals in tasks that require an understanding of the written system as a form of symbolic representation (Bialystok, Shenfield, \& Codd, 2000).

One study examined the differences in phonemic representation and early spelling errors in Mandarin-English DLLs who spoke either mostly Mandarin or mostly English (Yeong \& Liow, 2010). Using a cloze task, the researchers found that while spelling for common phonemes in English and Mandarin was equivalent for both groups of children, those children with Mandarin dominance showed poorer spelling of English-only phonemes. These results mirror those found in the phonological awareness studies described earlier, in 
which language proficiency in each language and differences in the phonological structure of the language have an influence in the development of phonemic awareness in DLLs.

Oral language abilities, early literacy, and early reading outcomes-Studies discussed in this section investigated the association between oral language and reading outcomes, the role of the home language in emergent literacy development, and the relation of emergent literacy abilities to later reading outcomes.

Of particular importance for DLL children is the relationship between oral language and emergent literacy skills. In older DLLs, oral language proficiency plays a critical role in reading comprehension (Geva, 2006). This relationship was found for young DLLs as well. Three studies found that oral language abilities in their L2 predicted DLL children's emergent literacy skills, their ability to identify letters and words in English in kindergarten and in first grade (Hammer et al., 2007; Rinaldi \& Páez, 2008; Tagoilelagi-LeotaGlynn, et al., 2005.), and reading comprehension by age 11 (Mancilla-Martínez \& Lesaux, 2011b). Additionally, Hammer et al. (2007) and Davison, Hammer, and Lawrence (2011) found that growth of children's Spanish and English oral language abilities during their two years in Head Start predicted their English emergent literacy and English and Spanish letter-word identification abilities in kindergarten and reading outcomes in first grade. However, Tagoilelagi-LeotaGlynn, et al. (2005) did not find cross-linguistic relationships. The difference in the design of the two studies may explain these conflicting findings.

Tagoilelagi-LeotaGlynn, et al. (2005) examined children's language abilities at one point in time whereas Hammer et al. (2007) documented language growth over children's two years in preschool. Moreover, in their longitudinal study, Mancilla-Martínez and Lesaux (2011b) found that children's growth in English word reading and vocabulary abilities (not Spanish) from ages 4.5 to 11 years predicted English comprehension skills at age 11. These results suggest that as children are exposed to English instruction over the years, they demonstrate less cross-linguistic transfer from their L1 to English.

Additionally, Rinaldi and Páez (2008) found that preschool English vocabulary and recalling skills and Spanish vocabulary were more predictive of English word reading skills in first grade than phonological awareness. These studies suggest that DLL children seem to use their knowledge in one language to support their literacy development of the other language, as has been found with older children (Dressler \& Kamil, 2006). However, these studies were conducted with DLLs who were exposed to English and Spanish, which share the same alphabetic system. Less is known about the oral language and literacy relationships in children who are learning two languages with different written systems.

In addition, one study investigated the role of home language usage on children's emergent literacy development (Hammer et al., 2009). Specifically, this investigation examined mothers' reported language usage over time and children's English emergent literacy development during children's two years in Head Start and kindergarten. Continued maternal usage of Spanish or increased usage of English over the three-year period had no impact on children's developing emergent literacy abilities in English. It was suggested that children's exposure to English in the classroom and community negated the influence of home language usage on emergent literacy development. 
One international study investigated the association between emergent literacy and later reading outcomes. The investigation, which involved Indian-English DLLs living in India, found that English recognition in kindergarten was related to later reading outcomes in English. This is similar to findings on monolinguals; however, the DLL children in this study struggled with reading comprehension in early elementary school (Sen \& Blatchford, 2001).

In summary, it appears that children's oral abilities in their L1 and L2 are related to later outcomes in each language. However, evidence is mixed as to whether cross-linguistic influences exist or if they only appear in the early childhood years. Preliminary findings showed the usage of L1 or L2 in the home does not impact emergent literacy development in the children's L2, and that L2 emergent literacy abilities in preschool are related to decoding in L2 in early elementary school.

Home language literacy environments-Three studies investigated the home literacy environments of DLL preschoolers and the relationship to literacy outcomes. The results of these studies are somewhat mixed. A study by Hammer, Miccio, and Wagstaff (2003) found no relationship between literacy events in the home and Spanish-English DLL children's emergent literacy abilities in Head Start. However, studies by Kalia (2007) and Kalia and Reese (2009) identified a relationship between Indian parents' book reading practices and teaching about print in English and children's English literacy abilities. The difference between these findings may be accounted for by the parents' educational status. The mothers who participated in Hammer et al.'s (2003) study averaged less than 12 years of education whereas the parents in Kalia's studies had a college education on average. Also, the context in which the children were raised may play a role. The families' participating in Hammer et al.'s study lived in the United States and the families in Kalia's studies lived in India. It is interesting to note that families in the studies did not read frequently. Mothers of simultaneous learners in Hammer et al.'s (2003) investigation read to their children 2-4 times per week and mothers of sequential learners read books to their children once a week on average. The mothers in Kalia's study reported reading "sometimes." It may be the maternal educational advantages of the children living in India explain the difference between the two studies.

\section{Discussion}

This review critically analyzed the research literature on the language and literacy development of young DLLs. Such a review is greatly needed given the increasing numbers of DLLs entering the educational system in the U.S. and the importance of children's early language and literacy development for later academic success. In the following sections, the key findings from the research on children's developmental trajectories are identified along with methodological concerns, gaps in the research base, and future research needs.

\section{Key Findings on DLLs' Language and Literacy Development}

Overall, this review demonstrated that great variability exists within the DLL population. Children vary with regard to their country of origin, the languages spoken, their experiences (both exposure and usage) with their two languages and their SES, among other 
characteristics. In addition, it was found that the majority of studies conducted on children living in the U.S. focused on Spanish speakers, who constitute the largest group of DLLs in the country by far.

The review also identified the range of research questions that were asked about children's language and literacy development during early childhood. Despite the range of questions, there were few studies conducted on any given question, making it difficult to come to a true consensus in most areas. Therefore, many of the conclusions provided in the following discussion should be considered preliminary.

First, there is solid evidence that DLLs have two separate language systems very early in life. This means that DLLs are not confused by being exposed two languages. However, influences between their two languages can be observed, although these influences may disappear over time. This conclusion is supported by studies that investigated phonology, vocabulary, grammar, pragmatics, and emergent writing.

Second, there is some evidence that the rate and development of DLLs' ability levels in each of their languages vary depending on when they were first exposed to their two languages. This evidence comes primarily from studies of children's vocabulary development.

Third, DLLs' development may differ from that of monolinguals in some areas of language and literacy, which makes sense given that DLLs are learning two languages and monolinguals are only learning one. For example, research on infants/toddlers' phonological (or speech sound) development indicates that DLLs phonological abilities are behind monolinguals early in life, but that they catch up to monolinguals during the preschool years. With regard to vocabulary development, DLLs' vocabularies in their individual languages are smaller than monolinguals; however, DLLs' conceptual vocabularies are equal to that of monolinguals during the first two to three years of life. When DLLs enter preschool, their vocabularies in their individual languages are below monolingual test norms. Evidence also suggests that DLLs' grammatical development follows a similar pattern as that of monolinguals, although it may take DLLs longer to achieve mastery of various morpho-syntactic constructions. With regard to children's literacy development, there is some evidence to suggest that DLLs enter preschool with literacy skills that are lower than those of monolinguals; however, these studies focused on children from lowincome homes. It appears that DLLs may catch up to monolinguals in letter-word knowledge in their second language. In addition, DLLs may have an advantage in their phonological awareness abilities over monolinguals, given DLLs' experiences with two languages. This advantage, however, may differ based on the languages spoken.

Fourth, little is known about factors that influence DLLs' language and literacy development. It appears that children's exposure to their two languages affects DLLs' language development, with more exposure to a particular language promoting children's abilities in that language. Also, preliminary evidence suggests that children's usage of their two languages, and not just exposure, should be considered. However, much more research is needed on factors that affect development to make a strong conclusion. 


\section{Methodological Concerns Encountered}

Numerous methodological issues were identified through the critical review. The first significant concern involved the size of the samples. Often, sample sizes were small, with many studies of infants and toddlers involving a single child. Second, there were limitations with respect to study design. Investigations often studied children at a particular point in time or were cross sectional.

Third, studies varied with regard to the definition of dual language learners used. This is a great concern. Often, a general definition was used or the criteria used to classify children as DLL were not well specified, if at all. Related to this, data on the characteristics of the samples were typically not provided or were limited (e.g., exposure and usage of two languages, demographic characteristics and SES). This makes it particularly difficult to draw conclusions, to generalize findings, or to make comparisons across studies.

Finally, most studies were impacted by the limited availability of valid and reliable assessment instruments in nearly all areas of language and literacy development. In general, the studies utilized assessment instruments of children's English language and literacy abilities that were standardized on monolingual samples. Instruments used to assess children's Spanish abilities often were developed on monolingual Spanish speakers from Latin America. Additionally, few standardized instruments are available to document the abilities of DLL children who speak languages other than Spanish and English. Given the lack of availability of instruments designed for DLL children, researchers had no choice but to use the limited tools available.

\section{Gaps in the Research and Future Needs}

Numerous gaps in the research exist. This section identifies the most significant gaps and research needs. The list should not be viewed as exhaustive. Instead, it should be considered a list of key areas were research is greatly needed.

First, there is a critical need for assessment instruments that are standardized on DLL populations. This includes instruments that can be used to assess children's abilities in English as well as their home language. Of course, this is not an easy task given the variation in the ages at which DLLs are exposed to their second language and the amount of exposure DLLs have to their two languages.

Second, there is a paucity of studies on DLLs' language and literacy development, particularly in comparison to the number of studies conducted on monolinguals. Of the research that has been conducted on DLL populations in the United States, most focused on Spanish-English DLLs, with few examining the development of children learning Asian languages, and even fewer focusing on other language groups. Although additional studies are needed that investigate the language development of Spanish-speaking children, there is a critical need for studies of DLL children from other language groups. Such investigations will assist the field in understanding how language development occurs when children are acquiring various home languages. Additionally, these investigations will help identify aspects of DLLs' development that are common to and that differ across languages and populations (Hammer et al., 2011). 
Related to the previous point, studies are greatly needed that examine DLLs' emergent reading and writing development, as well as the relationships among oral and written language development. In particularly, studies need to examine and compare the development of children learning alphabetic and non-alphabetic languages.

Third, there is a great need for longitudinal investigations that involve more than two data points. Specifically, studies are needed that examine children's development of their two languages and that study the relationship between children's languages over time. When conducting such studies, it will be imperative for researchers to carefully document the characteristics of the children and families, the languages spoken, children's experiences with their two languages (e.g., timing of exposure, amount of exposure and use, etc.) and changes in children's experiences with their two languages over time (Hammer, Lawrence, Rodriguez, Davison, \& Miccio, 2011). Additionally, there is a gap in coverage between research on infant/toddler bilingualism (i.e., studies that focus on children younger than two years) and research on preschool-aged DLL children and then follow the children through the elementary years. As a result, limited information exists about the course of early DLL development and how it affects children's school readiness and early school performance.

Fourth, additional research is needed on factors that influence language and literacy development among young DLL children, including characteristics of the children, their families and children's language experiences at home, childcare, and preschool. For example, studies are greatly needed that examine the differential effects of bilingualism and SES. The majority of studies that were conducted in the U.S. targeted children from families of low-SES or do not provide information about the children's SES. However, studies that involve children from various SES groups will assist the field in disentangling the effects of SES and bilingualism. Additionally, more information is needed on the effects of children's experiences (i.e., exposure and usage) on the development of their two languages, including acquiring a better understanding of the overall amount of experience with each language (as opposed to relative amount), the quality of input, and the effect on children's outcomes.

Finally, studies that investigate children's development in various language contexts and communities are needed. For example, it would be beneficial to compare the development of children who attend English-only programs versus programs that promote native language as well as English development. Similarly, research is required that investigates children who live in communities with varying concentrations of individuals who speak the children's L1. Related to this, the cultural context in which language and literacy development occurs needs to be considered, as language, communication and culture are inextricably linked.

Studies in each of these areas will greatly improve researchers', educators,' and policy makers' understanding of DLLs' language and literacy development. The findings from these studies, combined with the existing knowledge base, can then be used to inform interventions that are designed to promote children's academic outcomes and ultimately, children's overall well being. 


\section{Supplementary Material}

Refer to Web version on PubMed Central for supplementary material.

\section{Acknowledgements}

This manuscript was supported by grants from the Administration for Children and Families, Center for Early Care and Education Research: Dual Language Learners (90YR0041) and the National Institutes of Health-Eunice Kennedy Shriver National Institute of Child Health and Human Development (R01-HD051542, R01-HD068421, U01-HD060296).

Also, the authors would like to thank the following individuals for their valuable assistance with the review: Tracy Chin, Bonnie Jang, Karen Jury, Nadine Graham, Nora Whittaker Jones, Lindsay Powers, and Alexander Tucci.

\section{References1}

${ }^{1}$ References marked with an asterisk were included in the review.

*. Albareda-Castellot B, Pons F, Sebastián-Gallés N. The acquisition of phonetic categories in bilingual infants: New data from an anticipatory eye movement paradigm. Developmental Science. 2011; 2:395-401. [PubMed: 22213908]

*. Anderson RT. Phonological acquisition in preschoolers learning a second language via immersion: A longitudinal study. Clinical Linguistics \& Phonetics. 2004; 18:183-210. [PubMed: 15151191]

*. Anthony JL, Aghara RG, Solari EJ, Dunkelberger MJ, Williams JM, Liang L. Quantifying phonological representation abilities in Spanish-speaking preschool children. Applied Psycholinguistics. 2011; 32:19-49.

*. Anthony JL, Solari EJ, Williams JM, Schoger KD, Zhang Z, Branum-Martin L, Francis DJ. Development of bilingual phonological awareness in Spanish-speaking English language learners: The roles of vocabulary, letter knowledge, and prior phonological awareness. Scientific Studies of Reading. 2009; 13:535-564.

*. Anthony JL, Williams JM, Dura LK, Gillam SL, Liang L, Aghara R, Landry SH. Spanish phonological awareness: Dimensionality and sequence of development during the preschool and kindergarten years. Journal of Educational Psychology. 2011; 103:857-876.

August, D.; Shanahan, T. Developing literacy in second language learners. Report of the National Literacy Panel on Minority-Language Children and Youth. Mahwah, NJ: Lawrence Erlbaum; 2006.

*. Bader Y, Minnis DD. Morphological and syntactic code-switching in the speech of an ArabicEnglish bilingual child. Multilingua. 2000; 19:383-403.

Basterra, MR.; Trumbull, E.; Solano-Flores, G. Cultural validity in assessment: Address linguistic and cultural diversity. New York, NY: Routledge; 2010.

*. Bedore LM, Fiestas CE, Pena ED, Nagy VJ. Cross-language comparisons of maze use in Spanish and English in functionally monolingual and bilingual children. Bilingualism: Language and Cognition. 2006; 9:233-247.

*. Bedore LM, Peña ED, García M, Cortez C. Clinical forum. Conceptual versus monolingual scoring: When does it make a difference? Language, Speech \& Hearing Services in Schools. 2005; 36:188.

*. Bernardini P, Schlyter S. Growing syntactic structure and code-mixing in the weaker language: The ivy hypothesis. Bilingualism: Language and Cognition. 2004; 7:49-69.

Bialystok, E. Bilingualism in development: Language, literacy, and cognition. New York, NY: Cambridge University Press; 2001.

Bialystok E. Bilingualism: The good, the bad, and the indifferent. Bilingualism: Language and Cognition. 2009; 12:3-11.

*. Bialystok E, Barac R, Blaye A, Poulin-Dubois D. Word mapping and executive functioning in young monolingual and bilingual children. Journal of cognition and development: Official Journal of the Cognitive Development Society. 2010; 11:485-508. [PubMed: 21197133] 
Bialystok E, Herman J. Does bilingualism matter for early literacy? Bilingualism: Language and Cognition. 1999; 2:35-44.

*. Bialystok E, Luk G, Peets KF, Yang S. Receptive vocabulary differences in monolingual and bilingual children. Bilingualism: Language and Cognition. 2009:1-7.

*. Bialystok E, Shenfield T, Codd J. Languages, scripts, and the environment: Factors in developing concepts of print. Developmental Psychology. 2000; 36:66-76. [PubMed: 10645745]

Bird J, Bishop DVM, Freeman NH. Phonological awareness and literacy development in children with expressive phonological impairments. Journal of Speech and Hearing Research. 1995; 38:446462. [PubMed: 7596110]

*. Bland-Stewart L, Fitzgerald SM. Use of Brown's 14 grammatical morphemes by bilingual Hispanic preschoolers: A pilot study. Communication Disorders Quarterly. 2001; 22:171-186.

*. Blom E. Effects of input on the early grammatical development of bilingual children. International Journal of Bilingualism. 2010; 14:422-446.

*. Bohman TM, Bedore LM, Peña ED, Mendez-Perez A, Gillam RB. What you hear and what you say: Language performance in Spanish-English bilinguals. International Journal of Bilingual Education and Bilingualism. 2010; 13:325-344. [PubMed: 21731899]

*. Chilla S, Bonnesen M. A crosslinguistic perspective on child SLA: The acquisition of questions in German and French. Linguistische Berichte. 2011; 228:441-440.

*. Bosch L, Sebastián-Gallés N. Evidence of early language discrimination abilities in infants from bilingual environments. Infancy. 2001; 2:29-49.

*. Bosch L, Sebastián-Gallés N. Simultaneous bilingualism and the perception of a language-specific vowel contrast in the first year of life. Language and Speech. 2003; 46:217-243. [PubMed: 14748445]

*. Bowers EP, Vasilyeva M. The relation between teacher input and lexical growth of preschoolers. Applied Psycholinguistics. 2011; 32:221-241.

*. Brice AE, Carson CK, O'Brien JD. Spanish-English articulation and phonology of 4- and 5-year-old preschool children: An initial investigation. Communication Disorders Quarterly. 2009; 31:3-14.

Brown, R. A First Language. Cambridge, UK: Harvard Press; 1973.

*. Buckwalter JK, Gloria Lo Y. Emergent biliteracy in Chinese and English. Journal of Second Language Writing. 2002; 11:269-293.

*. Bunta F, Ingram D. The acquisition of speech rhythm by bilingual Spanish- and English-speaking 4and 5-year-old children. Journal of Speech, Language, and Hearing Research. 2007; 50:999_ 1014.

*. Bunta F, Fabiano-Smith L, Goldstein B, Ingram D. Phonological whole-word measures in 3-yearold bilingual children and their age-matched monolingual peers. Clinical Linguistics \& Phonetics. 2009; 23:156-175. [PubMed: 19197583]

*. Burns TC, Yoshida KA, Hill K, Werker JF. The development of phonetic representation in bilingual and monolingual infants. Applied Psycholinguistics. 2007; 28:455-474.

*. Camp BW, Cunningham M, Berman S. Relationship between the cognitive environment and vocabulary development during the second year of life. Archives of Pediatrics \& Adolescent Medicine. 2010; 164:950-956. [PubMed: 20921353]

*. Canbay O. Comparing the phonological awareness of bilingual and monolingual preschool children. Sciences-New York. 2011; 15:976-980.

*. Cantone KF, Muller N. 'Un nase or una nase'? What gender marking within switched DPs reveals about the architecture of the bilingual language faculty. Lingua. 2008; 118:810-826.

*. Castilla AP, Restrepo MA, Pérez-Leroux A. Individual differences and language interdependence: A study of sequential bilingual development in Spanish-English preschool children. International Journal of Bilingual Education and Bilingualism. 2009; 12:565-580.

*. Castro D, Gavruseva E. Finiteness and aspect in Spanish/English bilingual acquisition. First Language. 2003; 23:171-192.

*. Chang-Smith M. Developmental pathways for first language acquisition of Mandarin nominal expressions: Comparing monolingual with simultaneous Mandarin-English bilingual children. International Journal of Bilingualism. 2010; 14:11-35. 
*. Chung HH. Code switching as a communicative strategy: A case study of Korean-English bilinguals. Bilingual Research Journal. 2006; 30:293-307.

*. Comeau L, Genesee F, Mendelson M. Bilingual children's repairs of breakdowns in communication. Journal of Child Language. 2007; 34:159-174. [PubMed: 17340942]

*. Comeau L, Genesee F, Mendelson M. A comparison of bilingual and monolingual children's conversational repairs. First Language. 2010; 30:354-374.

*. Conboy BT, Mills DL. Two languages, one developing brain: Event-related potentials to words in bilingual toddlers. Developmental Science. 2006; 9:F1-F12. [PubMed: 16445386]

*. Conboy BT, Thal DJ. Ties between the lexicon and grammar: Cross-sectional and longitudinal studies of bilingual toddlers. Child Development. 2006; 77:712-735. [PubMed: 16686797]

Cummins, J. The role of primary language development in promoting educational success for language minority students. In: California State Department of Education., editor. Schooling and language minority students: A theoretical framework. Los Angeles, CA: National Dissemination and Assessment Center; 1981. p. 3-49.

*. Dahl TI, Rice C, Steffensen M, Amundsen L. Is it language relearning or language reacquisition? Hints from a young boy's code-switching during his journey back to his native language. International Journal of Bilingualism. 2010; 14(4):490-510.

*. David A, Wei L. Individual differences in the lexical development of French-English bilingual children. International Journal of Bilingual Education and Bilingualism. 2008; 11:598-618.

*. Davidson D, Raschke VR, Pervez J. Syntactic awareness in young monolingual and bilingual (UrduEnglish) children. Cognitive Development. 2010; 25:166-182.

*. Davison MD, Hammer C, Lawrence FR. Associations between preschool language and first grade reading outcomes in bilingual children. Journal of Communication Disorders. 2011; 44:444-458. [PubMed: 21477813]

*. Dickinson DK, McCabe A, Clark-Chiarelli N, Wolf A. Cross-language transfer of phonological awareness in low-income Spanish and English bilingual preschool children. Applied Psycholinguistics. 2004; 25:323-347.

Dixon LQ, Zhao J, Shin J-Y, Wu S, Su J-H, Burgess-Brigham R, Gezer MU, Snow CE. What we know about second language acquisition: A synthesis from four perspectives. Review of Educational Research. 2012; 82(1):5-60.

*. Dolitsky M. Codeswitching in a child's monologues. Journal of Pragmatics. 2000; 32:1387-1403.

Dressler, C.; Kamil, M. First- and second-language literacy. In: August, D.; Shanahan, T., editors. Developing literacy in second-language learners: Report of the National Literacy Panel on Language-Minority Children and Youth. Mahwah, NJ: Lawrence Erlbaum; 2006. p. 197-238.

Durgunoğlu AY, Nagy WE, Hancin-Bhatt BJ. Cross-language transfer of phonological awareness. Journal of Educational Psychology. 1993; 85:453-465.

*. Estrem TL. Expressive vocabulary development of immigrant preschoolers who speak Somali, Spanish, and Hmong. TESL-EJ: Teaching English as a Second or Foreign Language. 2011; 15:119.

*. Fabiano L, Goldstein B. Phonological cross-linguistic effects in bilingual Spanish-English speaking children. Journal of Multilingual Communication Disorders. 2005; 3:56-63.

*. Fabiano-Smith L, Barlow JA. Interaction in bilingual phonological acquisition: Evidence from phonetic inventories. International Journal of Bilingual Education and Bilingualism. 2010; 13:81-97. [PubMed: 20126516]

*. Fabiano-Smith L, Goldstein BA. Early-, middle-, and late-developing sounds in monolingual and bilingual children: An exploratory investigation. American Journal of Speech-Language Pathology. 2010a; 19:66-77. [PubMed: 19644127]

*. Fabiano-Smith L, Goldstein BA. Phonological acquisition in bilingual Spanish-English speaking children. Journal of Speech, Language, and Hearing Research. 2010b; 53:160-178.

*. Farver JAM, Xu Y, Eppe S, Lonigan CJ. Home environments and young Latino children's school readiness. Early Childhood Research Quarterly. 2006; 21:196-212.

*. Fennell CT, Byers-Heinlein K, Werker JF. Using speech sounds to guide word learning: The case of bilingual infants. Child Development. 2007; 78:1510-1525. doi:dx.doi.org/10.1111/j. 1467-8624.2007.01080.x. [PubMed: 17883445] 
*. Fernández Fuertes R, Liceras JM. Copula omission in the English developing grammar of English/ Spanish bilingual children. International Journal of Bilingual Education and Bilingualism. 2010; 13:525-551.

*. Foroodi-Nejad F, Paradis J. Crosslinguistic transfer in the acquisition of compound words in Persian-English bilinguals. Bilingualism: Language and Cognition. 2009; 12:411-427.

*. Foursha-Stevenson C, Nicoladis E. Early emergence of syntactic awareness and cross-linguistic influence in bilingual children's judgments. International Journal of Bilingualism. 2011; 15:521534.

*. Garcia-Sierra A, Rivera-Gaxiola M, Percaccio CR, Conboy BT, Romo H, Klarman L, Kuhl PK. Bilingual language learning: An ERP study relating early brain responses to speech, language input, and later word production. Journal of Phonetics. 2011; 39:546-557.

Geva, E. Second language oral proficiency and second language literacy. In: August, D.; Shanahan, T., editors. Developing literacy in second-language learners: A report of the national literacy panel on language minority children and youth. Mahwah, NJ: Erlbaum; 2006. p. 123-139.

*. Gildersleeve-Neumann C, Kester ES, Davis BL, Peña ED. English speech sound development in preschool-aged children from bilingual English-Spanish environments. Language, Speech, and Hearing Services in Schools. 2008; 39:314-328.

*. Gildersleeve-Neumann C, Peña ED, Davis BL, Kester ES. Effects on L1 during early acquisition of L2: Speech changes in Spanish at first English contact. Bilingualism: Language and Cognition. 2009; 12:259-272.

*. Gildersleeve-Neumann CE, Wright KL. English speech acquisition in 3- to 5-year-old children learning Russian and English. Language, Speech and Hearing Services in Schools. 2010; 41:429444.

*. Golberg H, Paradis J, Crago M. Lexical acquisition over time in minority first language children learning English as a second language. Applied Psycholinguistics. 2008; 29:41-65.

*. Goldstein BA, Bunta F, Lange J, Rodriguez J, Burrows L. The effects of measures of language experience and language ability on segmental accuracy in bilingual children. American journal of speech-language pathology/American Speech-Language-Hearing Association. 2010; 19:238247. [PubMed: 20484707]

*. Goldstein BA, Fabiano L, Washington PS. Phonological skills in predominantly English-speaking, predominantly Spanish-speaking, and Spanish-English bilingual children. Language, Speech, and Hearing Services in Schools. 2005; 36:201-218.

*. Goldstein B, Washington PS. An initial investigation of phonological patterns in typically developing 4-year old Spanish-English bilingual children. Language, Speech, and Hearing Services in Schools. 2001; 32:153-164.

Goodz N. Parental language mixing in bilingual families. Infant Mental Health Journal. 1989; 10:2544.

*. González JE, Uhing BM. Home literacy environments and young Hispanic children's English and Spanish oral language: A communality analysis. Journal of Early Intervention. 2008; 30:116139.

*. Gu CC. Crosslinguistic influence in two directions: The acquisition of dative constructions in Cantonese-English bilingual children. International Journal of Bilingualism. 2010; 14:87-103.

*. Guiberson MM, Barrett KC, Jancosek EG, Itano CY. Language maintenance and loss in preschoolage children of Mexican immigrants: Longitudinal study. Communication Disorders Quarterly. 2006; 28:4-17.

Halle T, Hair E, Wandener L, McNamara M, Chien N. Predictors and outcomes of early versus later English language proficiency. Early Childhood Quarterly. 2012; 27:1-20.

*. Hammer CS, Davison MD, Lawrence FR, Miccio AW. The effect of maternal language on bilingual children's vocabulary and emergent literacy development during Head Start and kindergarten. Scientific Studies of Reading. 2009; 13:99-121. [PubMed: 23606802]

Hammer CS, Jia G, Uchikoshi Y. Language and literacy development of dual language learners growing up in the United States: A call for research. Child Development Perspectives. 2011; 5(1): 4-9. [PubMed: 23259006] 
*. Hammer CS, Lawrence FR, Miccio AW. Bilingual children's language abilities and early reading outcomes in Head Start and kindergarten. Language, Speech \& Hearing Services in Schools. 2007; 38:237-248.

*. Hammer CS, Lawrence FR, Miccio AW. Exposure to English before and after entry into Head Start: Bilingual children's receptive language growth in Spanish and English. International Journal of Bilingual Education and Bilingualism. 2008a; 11:30-56.

*. Hammer CS, Lawrence FR, Miccio AW. The effect of summer vacation on bilingual preschoolers' language development. Clinical Linguistics \& Phonetics. 2008b; 22:686-702. [PubMed: 18608240]

*. Hammer CS, Lawrence FR, Rodriguez BL, Davison MD, Miccio AW. Changes in language usage of Puerto Rican mothers and their children: Do gender and timing of exposure to English matter? Applied Psycholinguistics. 2011; 32:275-297. [PubMed: 23258946]

*. Hammer CS, Miccio AW, Wagstaff DA. Home literacy experiences and their relationship to bilingual preschoolers' developing English literacy abilities: An initial investigation. Language, Speech, and Hearing Services in Schools. 2003; 34:20-30.

*. Hammer CS, Rodriguez BL, Lawrence FR, Miccio AW. Puerto Rican mothers' beliefs and home literacy practices. Language, Speech, and Hearing Services in Schools. 2007; 38:216-224.

Han W. Bilingualism and academic achievement. Child Development. 2012; 83:300-321. [PubMed: 22098584]

*. Hanson MJ, Miller AD, Diamond K, Odom S, Lieber J, Butera G, Fleming K. Neighborhood community risk influences on preschool children's development and school readiness. Infants \& Young Children. 2011; 24:87-100.

Hart, B.; Risley, TR. Meaningful differences in the everyday education of young American children. Baltimore, MD: Paul H. Brookes; 1995.

*. Hemsley G, Holm A, Dodd B. Patterns in diversity: Lexical learning in Samoan-English bilingual children. International Journal of Speech-Language Pathology. 2010; 12:362-374. [PubMed: 20441411]

Hoff E. The specificity of environmental influence: socioeconomic status affects early vocabulary development via maternal speech. Child Development. 2003; 7:1368-1378. [PubMed: 14552403]

Hoff E, Core C, Place S, Rumiche R, Señor M, Parra M. Dual language exposure and early bilingual development. Journal of Child Development. 2012; 39:1-27.

*. Holowka S, Brosseau-Lapré F, Petitto LA. Semantic and conceptual knowledge underlying bilingual babies' first signs and words. Language Learning. 2002; 52:205-262.

*. Jisa H. Language mixing in the weak language: Evidence from two children. Journal of Pragmatics. 2000; 32:1363-1386.

*. Johnson CE, Wilson IL. Phonetic evidence for early language differentiation: Research issues and some preliminary data. International Journal of Bilingualism. 2002; 6:271-289.

*. Juan-Garau M, Pérez-Vidal C. Subject realization in the syntactic development of a bilingual child. Bilingualism: Language and Cognition. 2000; 3:173-191.

*. Juan-Garau M, Pérez-Vidal C. Mixing and pragmatic parental strategies in early bilingual acquisition. Journal of Child Language. 2001; 28:59-86. [PubMed: 11258015]

*. Junker DA, Stockman IJ. Expressive vocabulary of German-English bilingual toddlers. American Journal of Speech-Language Pathology. 2002; 11:381-394.

*. Kalia V. Assessing the role of book reading practices in Indian bilingual children's English language and literacy development. Early Childhood Education Journal. 2007; 35:149-153.

*. Kalia V, Reese E. Relations between Indian children's home literacy environment and their English oral language and literacy skills. Scientific Studies of Reading. 2009; 13:122-145.

*. Kan PF, Kohnert K. Preschoolers learning Hmong and English: Lexical-semantic skills in L1 and L2. Journal of Speech, Language, and Hearing Research. 2005; 48:372.

*. Kan PF, Kohnert K. Fast mapping by bilingual preschool children. Journal of Child Language. 2008; 35:495-514. [PubMed: 18588712]

*. Kehoe M. Developing vowel systems as a window to bilingual phonology. International Journal of Bilingualism. 2002; 6:315-334. 
*. Kehoe MM, Lleó C, Rakow M. Voice onset time in bilingual German-Spanish children. Bilingualism: Language and Cognition. 2004; 7:71-88.

*. Kehoe MM, Lleo C, Rakow M. Speech Rhythm in the Pronunciation of German and Spanish Monolingual and German-Spanish Bilingual 3-Year-Olds. Linguistische Berichte. 2011; 2011:323-352.

*. Kenner C. Biliteracy in a monolingual school system?. English and Gujarati in south London. Language, Culture and Curriculum. 2000; 13:13-30.

*. Keshavarz MH. Halliday's communicative-functional model revisited: A case study. Communication Disorders Quarterly. 2001; 22:187-196.

*. Keshavarz MH. Morphological development in the speech of a Persian-English bilingual child. Journal of Psycholinguistic Research. 2007; 36:255-272. [PubMed: 17318436]

*. Keshavarz MH, Ingram D. The early phonological development of a Farsi-English bilingual child. International Journal of Bilingualism. 2002; 6:255-269.

*. Khattab G. /1/ production in English-Arabic bilingual speakers. International Journal of Bilingualism. 2002; 6:335-353.

*. Kim Y. Crosslinguistic influence on phonological awareness for Korean-English bilingual children. Reading and Writing: An Interdisciplinary Journal. 2009; 22:843-861.

*. Klammler A, Schneider S. The size and composition of the productive holophrastic lexicon: German-Italian bilingual acquisition vs. Italian monolingual acquisition. International Journal of Bilingual Education and Bilingualism. 2011; 14:69-88.

*. Kohnert K, Kan PF, Conboy BT. Lexical and grammatical associations in sequential bilingual preschoolers. Journal of Speech, Language, and Hearing Research: JSLHR. 2010; 53:684-698.

*. Komurcu B, Yildiz Y. An assessment of the auditory speech perceptual skills of young Turkish learners of English: Perceptual assimilation model. Procedia - Social and Behavioral Sciences. 2011; 15:3511-3515.

*. Kovács ÁM, Mehler J. Flexible learning of multiple speech structures in bilingual infants. Science. 2009; 325:611-612. [PubMed: 19589962]

Kuhl PK, Stevens E, Hayashi A, Deguchi T, Kiritani S, Iverson P. Infants show a facilitation effect for native language phonetic perception between 6 and 12 months. Developmental Science. 2006; 9:F13-F21. [PubMed: 16472309]

*. Kupisch T. Determiners in bilingual German-Italian children: What they tell us about the relation between language influence and language dominance. Bilingualism: Language and Cognition. 2007; 10:57-78.

*. Kyratzis A. Latina girls' peer play interactions in a bilingual Spanish-English U.S. preschool: Heteroglossia, frame-shifting, and language ideology. Pragmatics. 2010; 20:557-586.

*. Kyratzis A, Tang Y, Koymen SB. Codes, code-switching, and context: Style and footing in peer group bilingual play. Multilingua. 2009; 28:265-290.

*. Laurent A, Martinot C. Bilingualism and phonological segmentation of speech: The case of EnglishFrench preschoolers. Journal of Early Childhood Literacy. 2009; 9:29-49.

*. Leseman PPM. Bilingual vocabulary development of Turkish preschoolers in the Netherlands. Journal of Multilingual and Multicultural Development. 2000; 21:93-112.

*. Levey S, Cruz D. The first words produced by children in bilingual English/Mandarin Chinese environments. Communication Disorders Quarterly. 2003; 24(3):129-136.

*. Lin L, Johnson CJ. Phonological patterns in Mandarin-English bilingual children. Clinical Linguistics \& Phonetics. 2010; 24:369-386. [PubMed: 20345265]

*. Loizou M, Stuart M. Phonological awareness in monolingual and bilingual English and Greek fiveyear-olds. Journal of Research in Reading. 2003; 26:3-18.

*. López LM, Greenfield DB. The cross-language transfer of phonological skills of Hispanic Head Start children. Bilingual Research Journal. 2004; 28:1-18.

*. Lundén M, Silvén M. Balanced communication in mid-infancy promotes early vocabulary development: effects of play with mother and father in mono- and bilingual families. International Journal of Bilingualism. 2011; 15:535-559. 
*. MacLeod AAN, Laukys K, Rvachew S. The impact of bilingual language learning on whole-word complexity and segmental accuracy among children aged 18 and 36 months. International Journal of Speech-Language Pathology. 2011; 13:490-499. [PubMed: 21682544]

*. Mancilla-Martínez J, Lesaux NK. Early language use and later vocabulary development. Journal of Educational Psychology. 2011a; 103:535-566.

*. Mancilla-Martínez J, Lesaux NK. The gap between Spanish speakers' word reading and word knowledge: a longitudinal study. Child development. 2011b; 82:1544-1560. [PubMed: 21848955]

*. Marchman VA, Fernald A, Hurtado N. How vocabulary size in two languages relates to efficiency in spoken word recognition by young Spanish-English bilinguals. Journal of Child Language. 2010; 37:817-840. [PubMed: 19726000]

*. Marchman VA, Martínez-Sussman C, Dale PS. The language-specific nature of grammatical development: Evidence from bilingual language learners. Developmental Science. 2004; 7:212224. [PubMed: 15320381]

*. Marchman V, Martínez-Sussman C. Concurrent validity of caregiver/parent report measures of language for children who are learning both English and Spanish. Journal of Speech, Language, and Hearing Research. 2002; 45:983-997.

*. Marinova-Todd S, Zhao J, Bernhardt M. Phonological awareness skills in the two languages of Mandarin-English bilingual children. Clinical Linguistics \& Phonetics. 2010; 24:387-400. [PubMed: 20345266]

Mathematica Policy Research. Education policy research. 2010 Retrieved from http:// www.mathematica-mpr.com/.

*. Mattock K, Polka L, Rvachew S, Krehm M. The first steps in word learning are easier when the shoes fit: Comparing monolingual and bilingual infants. Developmental Science. 2010; 13:229_ 243. [PubMed: 20121879]

*. Messer MH, Leseman PPM, Boom J, Mayo AY. Phonotactic probability effect in nonword recall and its relationship with vocabulary in monolingual and bilingual preschoolers. Journal of Experimental Child Psychology. 2010; 105:306-323. [PubMed: 20116805]

*. Min H. A case study on parental discourse strategies and a bilingual child's code-mixing. Bulletin of Educational Psychology. 2011; 43:175-202.

*. Mishina-Mori S. Autonomous and interdependent development of two language systems in Japanese/English simultaneous bilinguals: Evidence from question formation. First Language. 2005; 25:291-315.

*. Mok PPK. The acquisition of speech rhythm by three-year-old bilingual and monolingual children: Cantonese and English. Bilingualism: Language and Cognition. 2011; 14:458-472.

*. Morita E. Children's use of address and reference terms: Language socialization in a JapaneseEnglish bilingual environment. Multilingua. 2003; 22:367-395.

Müller N. Transfer in bilingual first language acquisition. Bilingualism: Language and Cognition. 1998; 1:151-171.

*. Müller N, Hulk A. Crosslinguistic influence in bilingual language acquisition: Italian and French as recipient languages. Bilingualism: Language and Cognition. 2001; 4:1-53.

*. Mushi SLP. Acquisition of multiple languages among children of immigrant families: Parents' role in the home-school language pendulum. Early Child Development and Care. 2002; 172:517-530.

National Center for Education Statistics. Digest of education statistics. Washington, DC: U.S. Department of Education; 2013.

*. Nicholls RJ, Eadie PA, Reilly S. Monolingual versus multilingual acquisition of English morphology: what can we expect at age 3 ? International journal of language \& communication disorders / Royal College of Speech \& Language Therapists. 2011; 46:449-463. [PubMed: 21771220]

*. Nicoladis E. Cross-linguistic transfer in adjective-noun strings by preschool bilingual children. Bilingualism: Language and Cognition. 2006; 9:15-32.

*. Nicoladis E, Marchak K. Le Carte Blanc or la Carte Blanche? Bilingual Children's Acquisition of French Adjective Agreement. Language Learning. 2011; 61:734-758. 
*. Nicoladis E, Palmer A, Marentette P. The role of type and token frequency in using past tense morphemes correctly. Developmental Science. 2007; 10:237-254. [PubMed: 17286847]

*. Nicoladis E, Paradis J. Learning to liaise and elide comme il faut: evidence from bilingual children. Journal of child language. 2011; 38:701-730. [PubMed: 21029504]

Oller, DK.; Eilers, RE., editors. Language and literacy in bilingual children. Vol. 2. United Kingdom, UK: Multilingual Matters Ltd; 2002.

*. O'Shannessy C. Competition between word order and case-marking in interpreting grammatical relations: a case study in multilingual acquisition. Journal of child language. 2011; 38:763-792. [PubMed: 21054915]

*. Oades-Sese GV, Esquivel G, Kaliski P, Maniatis L. A longitudinal study of the social and academic competence of economically disadvantaged bilingual preschool children. Developmental Psychology. 2011; 47:747-764. [PubMed: 21219064]

*. Oades-Sese GV, Li Y. Attachment relationships as predictors of language skills for at-risk bilingual preschool children. Psychology in the Schools. 2011; 48:747-764.

Oller, DK.; Jarmulowicz, L. Language and literacy in bilinguals. In: Hoff, E.; Shatz, M., editors. Handbook of Language Development. Blackwell; 2007. p. 368-386.

*. Páez MM, Tabors PO, Lopez LM. Dual language and literacy development of Spanish-speaking preschool children. Journal of Applied Developmental Psychology. 2007; 28:85-102. [PubMed: 20396646]

Pan BA, Rowe ML, Singer JD, Snow CE. Maternal correlates of growth in toddler vocabulary production in low-income families. Child Development. 2005; 76:763-782. [PubMed: 16026495]

*. Paradis J. Do bilingual two-year-olds have separate phonological systems? International Journal of Bilingualism. 2001; 5:19-38.

*. Paradis J, Navarro S. Subject realization and crosslinguistic interference in the bilingual acquisition of Spanish and English: What is the role of the input? Journal of Child Language. 2003; 30:371393. [PubMed: 12846302]

*. Paradis J, Nicoladis E. The influence of dominance and sociolinguistic context on bilingual preschoolers' language choice. International Journal of Bilingual Education and Bilingualism. 2007; 10:277-297.

*. Paradis J, Nicoladis E, Genesee F. Early emergence of structural constraints on code-mixing: Evidence from French-English bilingual children. Bilingualism: Language and Cognition. 2000; 3:245-261.

*. Paradis J, Nicoladis E, Crago M, Genesee F. Bilingual children's acquisition of the past tense: a usage-based approach. Journal of child language. 2010; 38:554-578. [PubMed: 20738891]

*. Parra M, Hoff E, Core C. Relations among language exposure, phonological memory, and language development in Spanish-English bilingually-developing two-year-olds. Journal of Experimental Child Psychology. 2011; 108:113-125. [PubMed: 20828710]

*. Patterson JL. Observed and reported expressive vocabulary and word combinations in bilingual toddlers. Journal of Speech, Language, and Hearing Research. 2000; 43:121-128.

*. Patterson JL. Relationships of expressive vocabulary to frequency of reading and television experience among bilingual toddlers. Applied Psycholinguistics. 2002; 23:493-508.

Pearson, BZ. Raising a bilingual child. New York: Random House; 2008.

Pearson BZ, Fernández SC, Lewedeg V, Oller DK. The relation of input factors to lexical learning by bilingual infants. Applied Psycholinguistics. 1997; 18:41-58.

Pearson BZ, Fernández SC, Oller DK. Lexical development in bilingual infants and toddlers: Comparison to monolingual norms. Language Learning. 1993; 3(1):93-120.

Pearson BZ, Fernández SC, Oller DK. Cross-language synonyms in the lexicons of bilingual infants: One language or two? Journal of Child Language. 1995; 22:345-368. [PubMed: 8550727]

*. Pérez-Leroux AT, Cuza A, Thomas D. Clitic placement in Spanish-English bilingual children. Bilingualism: Language and Cognition. 2011; 14:221-232.

*. Perry NJ, Kay SM, Brown A. Continuity and change in home literacy practices of Hispanic families with preschool children. Early Child Development and Care. 2008; 178:99-113. 
*. Place S, Hoff E. Properties of dual language exposure that influence 2-year-olds' bilingual proficiency. Child development. 2011; 82:1834-1849. [PubMed: 22004372]

*. Qi R. Pronoun acquisition in a Mandarin-English bilingual child. International Journal of Bilingualism. 2010; 14(1):37-64.

*. Quiroz BG, Snow CE, Zhao J. Vocabulary skills of Spanish--English bilinguals: impact of mother-child language interactions and home language and literacy support. International Journal of Bilingualism. 2010; 14:379-399.

*. Ramon-Casas M, Swingley D, Sebastián-Gallés N, Bosch L. Vowel categorization during word recognition in bilingual toddlers. Cognitive Psychology. 2009; 59:96-121. [PubMed: 19338984]

*. Reyes I. Exploring connections between emergent biliteracy and bilingualism. Journal of Early Childhood Literacy. 2006; 6:267-292.

*. Reyes I, Azuara P. Emergent biliteracy in young Mexican immigrant children. Reading Research Quarterly. 2008; 43:374-398.

Riches, C.; Genesee, F. Literacy: Crosslinguistic and crossmodal issues. In: Genesee, F.; LindholmLeary, K.; Saunders, W.; Christian, D., editors. Educating English language learners: A synthesis of empirical findings. New York, NY: Cambridge University Press; 2006. p. 64-108.

*. Rinaldi C, Páez M. Preschool matters: Predicting reading difficulties for Spanish-speaking bilingual students in first grade. Learning Disabilities: A Contemporary Journal. 2008; 6:71-86.

*. Rohde A, Tiefenthal C. Aspects of lexical acquisition: Fast mapping in early L2 lexical acquisition. Studia Linguistica. 2000; 54:167-174.

*. Saiegh-Haddad E, Kogan N, Walters J. Universal and language-specific constraints on phonemic awareness: Evidence from Russian-Hebrew bilingual children. Reading and Writing. 2010; 23:359-384.

Scarborough, H. Connecting early language and literacy to later reading (dis)abilities: Evidence, theory and practice. In: Neumann, S.; Dickinson, D., editors. Handbook of early literacy. New York, NY: Guilford Press; 2001. p. 97-110.

Scarborough HS. Predicting the future achievement of second graders with reading disabilities: Contributions of phonemic awareness, verbal memory, rapid naming, and IQ. Annals of Dyslexia. 1998; 48:115-136.

*. Scarpino SE, Lawrence FR, Davison MD, Hammer CS. Predicting bilingual Spanish-English children's phonological awareness abilities from their preschool English and Spanish oral language. Journal of research in reading. 2011; 34:77-93. [PubMed: 23258945]

*. Scheele AF, Leseman PPM, Mayo AY. The home language environment of monolingual and bilingual children and their language proficiency. Applied Psycholinguistics. 2010; 31:117-140.

*. Schelletter C. The effect of form similarity on bilingual children's lexical development. Bilingualism: Language and Cognition. 2002; 5:93-107.

*. Schnitzer ML, Krasinski E. Idiosyncratic variation in the application of phonological processes in early bilingual acquisition. Language Sciences. 2003; 25:1-14.

*. Sebastián-Gallés N, Bosch L. Building phonotactic knowledge in bilinguals: Role of early exposure. Journal of Experimental Psychology: Human Perception and Performance. 2002; 28:974-989. [PubMed: 12190262]

*. Sebastián-Gallés N, Bosch L. Developmental shift in the discrimination of vowel contrasts in bilingual infants: Is the distributional account all there is to it? Developmental Science. 2009; 12:874-887. [PubMed: 19840043]

*. Sen R, Blatchford P. Reading in a second language: Factors associated with progress in young children. Educational Psychology. 2001; 21:189-202.

*. Serratrice L. Overt subjects in English: Evidence for the marking of person in an English-Italian bilingual child. Journal of Child Language. 2002; 29:327-355. [PubMed: 12109374]

*. Serratrice L, Sorace A, Paoli S. Crosslinguistic influence at the syntax-pragmatics interface: Subjects and objects in English-Italian bilingual and monolingual acquisition. Bilingualism: Language and Cognition. 2004; 7:183-205.

*. Sevinç M, Önkol FL. Language processing skills of 5-6 years old Turkish children attending monolingual and bilingual preschool education. Procedia Social and Behavioral Sciences. 2009; $1: 1378-1383$. 
*. Shafer VL, Yu YH, Datta H. The Development of English Vowel Perception in Monolingual and Bilingual Infants: Neurophysiological Correlates. Journal of phonetics. 2011; 39:527-545. [PubMed: 22046059]

*. Sheng L, Lu Y, Kan PF. Lexical development in Mandarin-English bilingual children. Bilingualism: Language and Cognition. 2011; 14:579-587.

*. Sheng L, McGregor KK, Marian V. Lexical-semantic organization in bilingual children: Evidence from a repeated word association task. Journal of Speech, Language, and Hearing Research. 2006; 49:572-587.

*. Shin SJ. Birth order and the language experience of bilingual children. TESOL Quarterly. 2002; 36:103-113.

*. Silva-Corvalán C. Early Spanish-English bilingualism: Theoretical issues, empirical analyses. Southwest Journal of Linguistics. 2007; 26:1-19.

*. Silva-Corvalán C, Montanari S. The acquisition of "ser," "estar" (and "be") by a Spanish-English bilingual child: The early stages. Bilingualism: Language and Cognition. 2008; 11:341-360.

*. Simon E. Child L2 development: A longitudinal case study on voice onset times in word-initial stops. Journal of Child Language. 2010; 37:159-173. [PubMed: 19323857]

Snow CE. Literacy and language: Relationships during the preschool years. Harvard Educational Review. 1983; 53:165-190.

Snow, CE.; Burns, MS.; Griffin, P. Preventing reading difficulties in young children. Washington, DC: National Academy Press; 1998.

*. Strand PS, Pula K, Parks CD, Cerna S. Shyness-anxiousness and receptive language skills development in Spanish- and English-speaking preschoolers. Journal of Applied Developmental Psychology. 2011; 32:363-368.

*. Sundara M, Scutellaro A. Rhythmic distance between languages affects the development of speech perception in bilingual infants. Journal of Phonetics. 2011; 39:505-513.

*. Sundara M, Polka L, Molnar M. Development of coronal stop perception: Bilingual infants keep pace with their monolingual peers. Cognition. 2008; 108:232-242. [PubMed: 18281027]

*. Tabors PO, Páez M, López LM. Dual language abilities of bilingual four-year olds: Initial findings from the early childhood study of language and literacy development of Spanish-speaking children. NABE Journal of Research and Practice. 2003; 1:70-91.

*. Tagoilelagi-LeotaGlynn F, McNaughton S, MacDonald S, Farry S. Bilingual and biliteracy development over the transition to school. International Journal of Bilingual Education \& Bilingualism. 2005; 8:455-479.

*. Tare M, Gelman SA. Bilingual parents' modeling of pragmatic language use in multiparty interactions. Applied Psycholinguistics. 2011; 32:761-780. [PubMed: 24086092]

*. Thordardottir E. The relationship between bilingual exposure and vocabulary development. International Journal of Bilingualism. 2011; 15:426-445.

Tseng V, Fuligni AJ. Parent-adolescent language use and relationships among immigrant families with east Asian, Filipino, and Latin American backgrounds. Journal of Marriage and Family. 2000; 62:465-476.

*. Vagh SB, Pan BA, Mancilla-Martínez J. Measuring growth in bilingual and monolingual children's English productive vocabulary development: The utility of combining parent and teacher report. Child Development. 2009; 80:1545-1563. [PubMed: 19765017]

*. Vihman MM, Thierry G, Lum J, Keren-Portnoy T, Martin P. Onset of word form recognition in English, Welsh, and English-Welsh bilingual infants. Applied Psycholinguistics. 2007; 28:475493.

*. Wei L, Lee S. L1 development in an L2 environment: The use of Cantonese classifiers and quantifiers by young British-born Chinese in Tyneside. International Journal of Bilingual Education and Bilingualism. 2001; 4:359-382.

*. Weikum WM, Vouloumanos A, Navarra J, Soto-Faraco S, Sebastián-Gallés N, Werker JF. Visual language discrimination in infancy. Science. 2007; 316(5828)

Werker JF, Lalonde CE. Cross-language speech perception: Initial capabilities and developmental change. Developmental Psychology. 1988; 24:672-683. 
Werker JF, Tees RC. Cross-language speech perception: Evidence for perceptual reorganization during the first year of life. Infant Behavior and Development. 1984; 7:49-63. doi.org/10.1016/ S0163-6383(84)80022-3.

Whitehurst G, Lonigan C. Child development and emergent literacy. Child Development. 1998; 69:848-872. [PubMed: 9680688]

*. Yaden DB, Tardibuono JM. The emergent writing development of urban Latino preschoolers: Developmental perspectives and instructional environments for second-language learners. Reading \& Writing Quarterly. 2004; 20:29-61.

*. Yavaş M. Patterns of cluster reduction in the acquisition of \#sC onsets: are bilinguals different from monolinguals? Clinical linguistics \& phonetics. 2011; 25:981-988. [PubMed: 22106888]

*. Yeong SHM, Liow SJR. Phonemic representation and early spelling errors in bilingual children. Scientific Studies of Reading. 2010; 14:387-406.

*. Yip V, Matthews S. Syntactic transfer in a Cantonese-English bilingual child. Bilingualism: Language and Cognition. 2000; 3:193-208.

*. Yip V, Matthews S. Relative clauses in Cantonese-English bilingual children: Typological challenges and processing motivations. Studies in Second Language Acquisition. 2007; 29:277300.

*. Yow WQ, Markman EM. Bilingualism and children's use of paralinguistic cues to interpret emotion in speech. Bilingualism: Language and Cognition. 2011; 14:562-569.

*. Zwanziger EE, Allen S, Genesee F. Crosslinguistic influence in bilingual acquisition: Subject omission in learners of Inuktitut and English. Journal of Child Language. 2005; 32:893.

[PubMed: 16429716] 


\section{Highlights}

- We conducted a critical literature review on language and literacy development of young dual language learners (DLLs).

- A total of 182 articles were identified and reviewed through the process.

- We identified numerous methodological concerns, including lack of a description of the language experiences of young DLLs.

- The studies addressed a wide range of research questions, making it difficult to make solid conclusions in most areas. 